\title{
Symposium review: Uncertainties in enteric methane inventories, measurement techniques, and prediction models ${ }^{1}$
}

\author{
A. N. Hristov, ${ }^{* 2}$ E. Kebreab,† M. Niu, $†$ J. Oh, ${ }^{*}$ A. Bannink, $\ddagger$ A. R. Bayat,§ T. M. Boland,\# A. F. Brito,II \\ D. P. Casper,ף L. A. Crompton,\$ J. Dijkstra,€ M. Eugène,¥ P. C. Garnsworthy, ${ }^{\star *}$ N. Haque,††

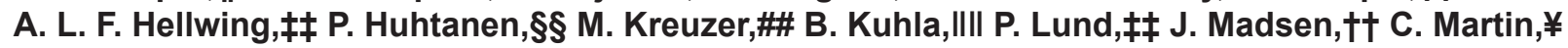 \\ P. J. Moate, $\rceil$ T S. Muetzel,\$\$ C. Muñoz,€€ N. Peiren,¥¥ J. M. Powell, ${ }^{* * *}$ C. K. Reynolds,\$ A. Schwarm,\#\#

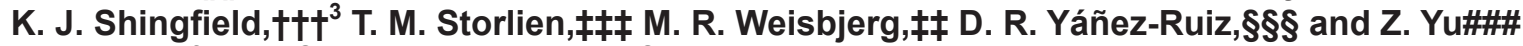 \\ *Department of Animal Science, The Pennsylvania State University, University Park 16802 \\ †Department of Animal Science, University of California, Davis 91616 \\ ¥Wageningen Livestock Research, Wageningen University and Research, $6700 \mathrm{AH}$ Wageningen, the Netherlands \\ §Milk Production Solutions, Green Technology, Natural Resources Institute Finland, 31600 Jokioinen, Finland \\ \#School of Agriculture and Food Science, University College Dublin, Belfield, Dublin 4, Ireland \\ IIDepartment of Nutrition, Agriculture, and Food Systems, University of New Hampshire, Durham 03824 \\ TFurst McNess Company, Freeport, IL 61032 \\ \$School of Agriculture, Policy and Development, University of Reading, Earley Gate, RG6 6AR, United Kingdom \\ $€$ Animal Nutrition Group, Wageningen University and Research, $6700 \mathrm{AH}$ Wageningen, the Netherlands \\ ¥UMR Herbivores, INRA, VetAgro Sup, Université Clermont Auvergne, 63122 Saint-Genès-Champanelle, France \\ ** School of Biosciences, University of Nottingham, Loughborough, LE12 5RD, United Kingdom \\ ††Department of Large Animal Sciences, University of Copenhagen, 1870 Frederiksberg, Denmark \\ ¥¥Department of Animal Science, Aarhus University, Foulum, 8830 Tjele, Denmark \\ $\S \S D$ partment of Agricultural Science for Northern Sweden, Swedish University of Agricultural Sciences, SE-901 87 Umeå, Sweden \\ \#\#ETH Zurich, Institute of Agricultural Sciences, 8092 Zurich, Switzerland \\ \|IIIInstitute of Nutritional Physiology, Leibniz Institute for Farm Animal Biology, 18196 Dummerstorf, Germany \\ ITTAgriculture Victoria, Ellinbank, Victoria 3821, Australia \\ \$\$Ag Research, Palmerston North 4442, New Zealand \\ €€Instituto de Investigaciones Agropecuarias, INIA Remehue, Osorno, Región de Los Lagos 5290000, Chile \\ $¥ ¥ A$ nimal Sciences Unit, Flanders Research Institute for Agriculture, Fisheries and Food, 9090 Melle, Belgium \\ ***USDA-ARS US Dairy Forage Research Center, Madison, WI 53706 \\ †††Institute of Biological, Environmental and Rural Sciences, Aberystwyth University, Aberystwyth SY23 3EB, United Kingdom

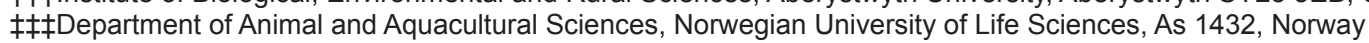 \\ $\S \S \S$ Estación Experimental del Zaidin, CSIC, 1, 18008 Granada, Spain \\ \#\#\#Department of Animal Sciences, The Ohio State University, Columbus 43210
}

\section{ABSTRACT}

Ruminant production systems are important contributors to anthropogenic methane $\left(\mathrm{CH}_{4}\right)$ emissions, but there are large uncertainties in national and global livestock $\mathrm{CH}_{4}$ inventories. Sources of uncertainty in enteric $\mathrm{CH}_{4}$ emissions include animal inventories, feed dry matter intake (DMI), ingredient and chemical composition of the diets, and $\mathrm{CH}_{4}$ emission factors. There is also significant uncertainty associated with enteric $\mathrm{CH}_{4}$ measurements. The most widely used techniques are respiration chambers, the sulfur hexafluoride $\left(\mathrm{SF}_{6}\right)$ tracer technique, and the automated head-chamber sys-

Received July 20, 2017.

Accepted March 25, 2018.

${ }^{1}$ Presented as part of the Production, Management, and the Environment Symposium: Greenhouse Gas Emissions from Dairy Operations at the ADSA Annual Meeting in Pittsburgh, Pennsylvania, in June 2017.

${ }^{2}$ Corresponding author: anh13@psu.edu

${ }^{3}$ Deceased. tem (GreenFeed; C-Lock Inc., Rapid City, SD). All 3 methods have been successfully used in a large number of experiments with dairy or beef cattle in various environmental conditions, although studies that compare techniques have reported inconsistent results. Although different types of models have been developed to predict enteric $\mathrm{CH}_{4}$ emissions, relatively simple empirical (statistical) models have been commonly used for inventory purposes because of their broad applicability and ease of use compared with more detailed empirical and process-based mechanistic models. However, extant empirical models used to predict enteric $\mathrm{CH}_{4}$ emissions suffer from narrow spatial focus, limited observations, and limitations of the statistical technique used. Therefore, prediction models must be developed from robust data sets that can only be generated through collaboration of scientists across the world. To achieve high prediction accuracy, these data sets should encompass a wide range of diets and production systems within regions and globally. Overall, enteric $\mathrm{CH}_{4}$ prediction models are based on various animal or feed character- 
istic inputs but are dominated by DMI in one form or another. As a result, accurate prediction of DMI is essential for accurate prediction of livestock $\mathrm{CH}_{4}$ emissions. Analysis of a large data set of individual dairy cattle data showed that simplified enteric $\mathrm{CH}_{4}$ prediction models based on DMI alone or DMI and limited feed- or animal-related inputs can predict average $\mathrm{CH}_{4}$ emission with a similar accuracy to more complex empirical models. These simplified models can be reliably used for emission inventory purposes.

Key words: enteric methane, uncertainty, prediction model, livestock

\section{INTRODUCTION}

The livestock sector is a significant source of anthropogenic greenhouse gas (GHG) emissions. In the United States, emissions from livestock production contributed an estimated $48 \%$ of the 2015 agricultural GHG emissions (US EPA, 2017). In Europe (EU-28), $59 \%$ of estimated agricultural GHG emissions were from livestock in 2015 (http://ec.europa.eu/eurostat/ web/agriculture/data/database; accessed December 5, 2017). Methane $\left(\mathrm{CH}_{4}\right)$ and nitrous oxide are the 2 most important GHG from agricultural activities. Methane, a potent short-lived (12.2-yr lifetime; Myhre et al., 2013) GHG, is emitted from livestock operations through enteric fermentation in the animal's gastrointestinal tract (reticulo-rumen and hindgut) and similar methanogenic processes in manure. Globally, enteric $\mathrm{CH}_{4}$ emissions

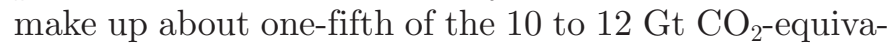
lent/yr GHG emissions from the Agriculture, Forestry, and Other Land Use sector (IPCC, 2014). There are, however, large uncertainties associated with estimating GHG emissions from livestock (or any other source), which has led to discrepancies between top-down (i.e., based on atmospheric measurements) and bottom-up (based on national or regional activity data and emission factors for different $\mathrm{CH}_{4}$ sources) and among bottomup $\mathrm{CH}_{4}$ emission inventories (Miller et al., 2013; Hristov et al., 2014, 2017; Wecht et al., 2014; Maasakkers et al., 2016). These uncertainties may be related to uncertainties in changes in $\mathrm{CH}_{4}$ sinks (Rigby et al., 2017), or to uncertainties in changes in $\mathrm{CH}_{4}$ sources. As an example, a recent bottom-up inventory analysis, based mostly on national inventory reports, suggested that global livestock $\mathrm{CH}_{4}$ emissions are $11 \%$ greater than estimates based on Intergovernmental Panel on Climate Change (IPCC) emission factors (Wolf et al., 2017). As an $11 \%$ difference is well within the uncertainty bounds for livestock $\mathrm{CH}_{4}$ inventories (Hristov et al., 2017; US EPA, 2017), conclusions from such analyses have to be interpreted with caution. Therefore, the objective of this paper was to review uncertainties and discrepan- cies in $\mathrm{CH}_{4}$ inventories as related to livestock emissions, enteric $\mathrm{CH}_{4}$ measurement methods, and DMI and $\mathrm{CH}_{4}$ prediction models. The review and data presented here are an integral part of the GLOBAL NETWORK project and the Feed and Nutrition Network (http:// animalscience.psu.edu/fnn/current-research/global -network-for-enteric-methane-mitigation; accessed December 4, 2017) within the Livestock Research Group of the Global Research Alliance for Agricultural Greenhouse Gases (www.globalresearchalliance.org; accessed December 4, 2017).

\section{UNCERTAINTIES IN ATMOSPHERIC METHANE CONCENTRATIONS AND ATTRIBUTION TO LIVESTOCK SOURCES}

Globally, atmospheric mixing ratio of $\mathrm{CH}_{4}$ (the number of moles of $\mathrm{CH}_{4}$ per mole of air) was relatively stable between 1999 and 2006 but have increased continuously since 2006 at a rate of 4 to $12 \mathrm{nmol} / \mathrm{mol}$ per year (https://www.esrl.noaa.gov/gmd/ccgg/trends_ch4/ \#global_growth; accessed June 16, 2017). There is no consensus about the major drivers for this increase and, in addition, there is considerable disagreement regarding the contribution of livestock to global $\mathrm{CH}_{4}$ emissions. Reports based on isotopic composition of $\mathrm{CH}_{4}$ in the atmosphere, ice cores, and archived air, or combined data from bottom-up and top-down methodologies suggested that post-2006 increases in $\mathrm{CH}_{4}$ emissions are predominantly caused by increases in microbial $\mathrm{CH}_{4}$ (Nisbet et al., 2016; Saunois et al., 2016; Schaefer et al., 2016). Microbial, or biogenic, $\mathrm{CH}_{4}$ is generated by methanogenic archaea and can be from wetlands and agricultural activities, mainly livestock production and rice cultivation (Stolper et al., 2015). The atmospheric mixing ratio of $\mathrm{CH}_{4}$ is a function of emissions and sinks. The major sink for atmospheric $\mathrm{CH}_{4}$ is oxidation by hydroxyl radicals $(\mathrm{OH})$, occurring mostly in the troposphere, which accounts for approximately $90 \%$ of the global $\mathrm{CH}_{4}$ sink (Kirschke et al., 2013). Because of the short lifetime of $\mathrm{OH}$, direct observations of atmospheric $\mathrm{OH}$ mixing ratio are difficult to accomplish (Rigby et al., 2017). Therefore, the increase in atmospheric $\mathrm{CH}_{4}$ cannot be reliably attributed to an overall increase in emissions. The analysis by Rigby et al. (2017) pointed to "significant OH-related uncertainties" in the atmospheric $\mathrm{CH}_{4}$ budget and concluded that it is impossible to implicate global $\mathrm{CH}_{4}$ emission changes as the primary driver for recent trends in atmospheric $\mathrm{CH}_{4}$ mixing ratio.

If there was an increase in atmospheric $\mathrm{CH}_{4}$ mixing ratio and the increase was caused by agricultural sources, specifically livestock emissions, the trends in atmospheric $\mathrm{CH}_{4}$ should correspond to dynamics in global 
livestock populations. During 1999 to 2006, however, when atmospheric $\mathrm{CH}_{4}$ mixing ratio plateaued, global cattle and buffalo populations (these species make up $84 \%$ of all livestock enteric $\mathrm{CH}_{4}$ emissions; FAOSTAT, 2017 ) continued to increase from 1.46 (1999) to 1.59 (2006) billion head (FAOSTAT, 2017), at a rate of approximately 18.8 million head/yr, which apparently did not affect atmospheric $\mathrm{CH}_{4}$ over the same period. Since 2006, the rate of increase for the populations of these ruminant species declined to 7.3 million head/yr (FAOSTAT, 2017); we note that FAOSTAT does not specify uncertainty for their estimates, which is likely large for cattle inventories (and emission factors) in developing countries. Thus, it appears that the global dynamics in large ruminant inventories do not support the suggested farmed livestock origin of the increase in atmospheric $\mathrm{CH}_{4}$ from 2006 to 2015. Potential increases in $\mathrm{CH}_{4}$ emission from non-livestock agricultural sources to the global $\mathrm{CH}_{4}$ budget cannot be excluded. Globally, the area harvested for paddy rice (emissions from which are typically 22 to $24 \%$ of the emissions from livestock), for example, had increased $42 \%$ from the 1960s to 2015 (FAOSTAT, 2017), although new rice varieties (i.e., water-saving and drought-resistance rice, or WDR; Luo, 2010) require less water and thus emit less $\mathrm{CH}_{4}$ (Sun et al., 2016).

Source attribution of atmospheric $\mathrm{CH}_{4}$ is largely based on its stable isotope signature, specifically ${ }^{13} \mathrm{C} /{ }^{12} \mathrm{C}$. The average isotopic signature of microbial $\mathrm{CH}_{4}$ appears to be quite distinct from that of fossil fuel $\mathrm{CH}_{4}$ (Wang et al., 2015; Schwietzke et al., 2016). In the Wang et al. (2015) study, average $\delta^{13} \mathrm{C}$ of thermogenic $\mathrm{CH}_{4}$ from the Northern Appalachian Basin was -36.2 to $-25.7 \%$, whereas ${ }^{13} \mathrm{C}$ of enteric $\mathrm{CH}_{4}$ from cows from the Pennsylvania State University's dairy herd was -54.2 to -52.8 $\%$. Based on $\mathrm{CH}_{4}$ isotopic signature data, Schwietzke et al. (2016) concluded that fossil fuel $\mathrm{CH}_{4}$ emissions are not increasing over time, implying that emissions of $\mathrm{CH}_{4}$ from microbial sources have been increasing. Examination of the $\delta^{13} \mathrm{CH}_{4}$ database used in the Schwietzke et al. (2016) study (https://www.esrl.noaa.gov/ gmd/ccgg/d13C-src-inv/; accessed December 4, 2017), however, shows a relatively large variability and uncertainty in the $\delta^{13} \mathrm{CH}_{4}$ data, from $-68 \%$ ( $\left.\mathrm{SD}=3.0 \%\right)$ for C3 plant-based ruminant diets to $-54 \%(\mathrm{SD}=3.0)$ for $\mathrm{C} 4$ plant diets; the authors used $\delta^{13} \mathrm{CH}_{4}$ of $-66.8 \pm$ $2.8 \%$ as a global average for ruminants, which is very close to that for wetlands $(-61.5 \pm 0.6 \%)$. Wang et al. (2015) also reported similar $\delta^{13} \mathrm{CH}_{4}$ for ruminal and swamp $\mathrm{CH}_{4}$ samples. In the Schwietzke et al. (2016) database (over 8,100 observations), $\delta^{13} \mathrm{CH}_{4}$ of fossil fuel $\mathrm{CH}_{4}$ (average of $-45.0 \pm 6.96 \%$ with minimum and maximum of -64.1 and $-29.1 \%$, respectively) had a standard deviation as high as 15 to $16 \%$. This large variability in the isotopic signatures of microbial and fossil fuel $\mathrm{CH}_{4}$ requires a more cautious interpretation of the data on $\mathrm{CH}_{4}$ emission source distribution and the conclusions of Schwietzke et al. (2016). Furthermore, a recent analysis by Turner et al. (2017) showed significant overlap in the $\delta^{13} \mathrm{CH}_{4}$ isotopic signatures of fossil fuel $(-15$ to $-76 \%)$ and non-fossil-fuel $(-31$ to $-93 \%)$ $\mathrm{CH}_{4}$ sources. As pointed out by Turner et al. (2017), fossil fuel $\mathrm{CH}_{4}$ is not entirely thermogenic in origin (based on its isotopic signature), with over $20 \%$ of the world's natural gas reserves generated by microbial activities (i.e., carrying biogenic isotopic signature). Thus, collectively, we can conclude that quantitative attribution of changes in atmospheric $\mathrm{CH}_{4}$ concentrations to $\mathrm{CH}_{4}$ sources based on $\delta^{13} \mathrm{CH}_{4}$ data is at least questionable. Both enteric and manure emissions contribute to livestock $\mathrm{CH}_{4}$, with manure reportedly being less depleted in ${ }^{13} \mathrm{C}$ than enteric $\mathrm{CH}_{4}$, which further decreases the usefulness of the $\delta^{13} \mathrm{CH}_{4}$ signature approach for estimating the share of microbially derived $\mathrm{CH}_{4}$ (Klevenhusen et al., 2010). Additional isotope measurements such as ${ }^{14} \mathrm{CH}_{4}$, hydrogen isotopes, deuteromethane, or clumped isotopes (heavy isotopes that are bonded to other heavy isotopes; Eiler, 2007; Stolper et al., 2015; Wang et al., 2015) would help better discriminate individual source contributions.

\section{UNCERTAINTIES IN LIVESTOCK METHANE INVENTORIES}

Globally, estimated non- $\mathrm{CO}_{2}$ GHG emissions from agriculture increased at a rate of $0.9 \% / y r$ between 1990 and 2010 (IPCC, 2014). In the United States, the Environmental Protection Agency (US EPA, 2017) reported a $16 \%$ decrease in $\mathrm{CH}_{4}$ emissions between 1990 and 2015, due mainly to estimated decreases in emissions associated with fossil fuel exploration and production. The EPA's bottom-up $\mathrm{CH}_{4}$ inventory was challenged by top-down analyses suggesting that livestock $\mathrm{CH}_{4}$ emissions are underestimated by as much as $80 \%$ by the EPA (Miller et al., 2013; Wecht et al., 2014). In the Wecht et al. (2014) study, oil and gas emissions, the largest source of anthropogenic $\mathrm{CH}_{4}$ in the United States, were estimated to be $20 \%$ lower than EPA's bottom-up estimates. A more recent top-down analysis indicated a sharp 30\% increase in anthropogenic $\mathrm{CH}_{4}$ emissions in the United States between 2002 and 2014 (Turner et al., 2016). According to their study, the spike in atmospheric $\mathrm{CH}_{4}$ was mainly over the central part of the United States. Although the authors (Turner et al., 2016) mentioned a 20\% increase in oil and gas production and a 9-fold increase in shale gas production in the United States (from 2002 to 2014), they concluded that the data do not allow attribution 
of atmospheric $\mathrm{CH}_{4}$ mixing ratio to a specific source. It is worth pointing out that the cattle population (the major source of livestock enteric and manure $\mathrm{CH}_{4}$ emissions) in the United States has been declining since the late 1970s, from 111 million in 1980 to 92 million in 2016 (NASS, 2017). Body weight of beef (and dairy) cattle has been increasing, however; as an example, despite the decreasing beef cattle numbers, total beef slaughter production has increased from about 107 to 125 million kilograms from 1980 to 2016 (NASS, 2017). This increase in the live and carcass weight of cattle, which likely corresponds to greater DMI, will partially offset the potential decrease in enteric $\mathrm{CH}_{4}$ emission from the beef sector in the United States, caused by decreasing cattle inventories.

The uncertainties in livestock enteric $\mathrm{CH}_{4}$ emissions in the current US EPA (2017) report are -11 and $18 \%$ (lower and upper bounds, respectively), corresponding to a $95 \%$ confidence interval, with the lower bound corresponding to the 2.5th percentile and the upper bound corresponding to 97.5 th percentile, respectively. For $\mathrm{CH}_{4}$ emissions from manure management, the uncertainty is -18 and $20 \%$, respectively (US EPA, 2017). These uncertainties result from several factors, including uncertainties in animal inventories, DMI, ingredient and chemical composition of the diet, and $\mathrm{CH}_{4}$ emission factors (for enteric fermentation) and inaccuracies of measurement of $\mathrm{CH}_{4}$ emission from manure (minute amounts, often emitted as bubbles) related to manure composition, manure management system, duration of manure storage, and environmental factors such as temperature and wind. A recent gridded $\left(0.1^{\circ} \times 0.1^{\circ}\right.$ grid; which represents an area of 81 to 109 $\mathrm{km}^{2}$ ) inventory of livestock $\mathrm{CH}_{4}$ emissions in the continental United States reported lower and upper 95\% confidence bounds of -15.6 and $16.9 \%$ (as \% of the mean; enteric), -65.0 and $63.3 \%$ (manure), and -19.3 and $19.2 \%$ (total emissions), respectively (Hristov et al., 2017). In that analysis, major sources of uncertainties for enteric $\mathrm{CH}_{4}$ were animal BW (lower and upper 95\% confidence bounds across cattle categories: -18 to $-24 \%$ and 21 to $29 \%$, respectively), DMI ( -21 to $-29 \%$ and 21 to $29 \%$ ), and $\mathrm{CH}_{4}$ yield ( -18 to $-41 \%$ and 19 to $42 \%$ ). In a model designed to estimate enteric $\mathrm{CH}_{4}$ from Dutch dairy farms, Bannink et al. (2011) reported that the largest uncertainty $(18 \%)$ was related to VFA stoichiometry. Estimates for total livestock $\mathrm{CH}_{4}$ emissions in the Hristov et al. (2017) study were comparable to current US EPA (2017) estimates for 2012 (last census of agriculture) and to estimates from the gridded Emission Database for Global Atmospheric Research (EDGAR, 2011) inventory. However, the spatial distribution of emissions in the Hristov et al. (2017) analysis differed significantly from that of EDGAR and a recent gridded inventory based on US EPA's emission database (Maasakkers et al., 2016). For example, the combined enteric and manure $\mathrm{CH}_{4}$ emissions from livestock in Texas and California (the largest contributors to the national total) in the Hristov et al. (2017) study were $36 \%$ lower and $100 \%$ greater, respectively, than estimates from EDGAR. These differences originate from differences in emission factors between the 2 analyses [lower emission factors for feedlot cattle (i.e., Texas) and higher emission factors for dairy cows (i.e., California) in the Hristov et al., 2017 analysis]. Gridded bottom-up emission inventories, such as EDGAR, are commonly used to assess the contribution of $\mathrm{CH}_{4}$ from different sectors within a region. Top-down approaches use these bottom-up inventories as a prior estimate of total emissions and, in some cases, to allocate the resulting (posterior) emission estimates to emission sources (Saunois et al., 2016). As a result, spatial distribution of emissions in gridded inventories likely strongly affects the conclusions of top-down approaches that use them, especially in the source attribution of emissions (i.e., biogenic vs. thermogenic or livestock vs. fossil fuel); therefore, conclusions from such studies should be interpreted with caution, even more when aiming to make future projections and evaluate mitigation options.

\section{UNCERTAINTIES IN ENTERIC METHANE MEASUREMENT TECHNIQUES}

Several established techniques exist for direct measurement of enteric $\mathrm{CH}_{4}$ emissions from ruminants. These include respiration chambers (RC), the sulfur hexafluoride $\left(\mathrm{SF}_{6}\right)$ tracer technique, and more recently, the GreenFeed technique (GF; C-Lock Inc., Rapid City, SD), which is an automated head-chamber system. In addition, several indirect techniques have also been proposed and used for measuring enteric $\mathrm{CH}_{4}$ emissions (reviewed by Negussie et al., 2017). A comprehensive review of current enteric $\mathrm{CH}_{4}$ measurement techniques was recently published by an international team of scientists (Hammond et al., 2016a) as part of the GLOBAL NETWORK project.

The GLOBAL NETWORK project has collected thousands of measurements of $\mathrm{CH}_{4}$ emissions from individual animals and accompanying data (e.g., diet composition and DMI) to develop robust, broadly applicable $\mathrm{CH}_{4}$ prediction equations for applications such as livestock $\mathrm{CH}_{4}$ inventories. Contributors supplying data to the GLOBAL NETWORK project used various methods for measuring enteric $\mathrm{CH}_{4}$. Three databases were created, one each for dairy cows, beef cattle, and small ruminants (sheep and goats). In Table 1, we present data for the main measurement techniques that 
were included in the dairy database of the GLOBAL NETWORK project. The RC sub-database included cows with DMI and milk yield that were lower than those of cows included in the GF sub-data set but comparable to those in the $\mathrm{SF}_{6}$ data set. Also, the range of $\mathrm{DMI}$ was narrower for $\mathrm{GF}$ and $\mathrm{SF}_{6}$ than for $\mathrm{RC}$. As evident from the data, significant variation was associated with all measurement methods for $\mathrm{CH}_{4}$ emission rate, yield, and intensity; the coefficient of variation $(\mathbf{C V})$ for emission rate ( $\mathrm{g}$ of $\mathrm{CH}_{4} / \mathrm{d}$ ) averaged 30, 18, and $28 \%$ for $\mathrm{RC}, \mathrm{GF}$, and $\mathrm{SF}_{6}$, respectively. It is important to note that the variability included in these CV values includes all sources of variation, not just variation due to method of measurement and how it was used. Methane emission rate is determined primarily by the amount of rumen fermentable substrate and, for this reason, comparisons of $\mathrm{CV}$ are better made based on $\mathrm{CH}_{4}$ yield; that is, grams of $\mathrm{CH}_{4}$ per kilogram of DMI. On this basis, the $\mathrm{CV}$ for $\mathrm{RC}$ is reduced to $21 \%$ and is comparable to that for $\mathrm{GF}$ and $\mathrm{SF}_{6}$ (21 and $27 \%$, respectively). Low variability, however, does not always mean high accuracy. Each method has to be carefully evaluated by researchers who, based on their expertise and available data, can determine whether a method can be reliably used to measure enteric $\mathrm{CH}_{4}$ emission from ruminants for the specific conditions and objectives of their experiment and animals used.

\section{Respiration Chambers}

Respiration chambers have been considered the gold standard for measuring enteric $\mathrm{CH}_{4}$ emission from farm animals, although this is only the case if $\mathrm{RC}$ are operated properly and recoveries are fixed and preferably close to $100 \%$. Moreover, there are many kinds of chambers and operation procedures with varying accuracies. As shown in a collaborative project in the United Kingdom, RC can also produce inaccurate results (Gardiner et al., 2015). In that ring-test, measured $\mathrm{CH}_{4}$ recovery was unacceptably low for several of the RC tested. Critical sources of variation for measurement of $\mathrm{CH}_{4}$ emission through $\mathrm{RC}$ are airflow rate through the chamber and the dynamics of air mixing in the chamber, which determines response time. In the ring-test by Gardiner et al. (2015), 3 potential sources of experimental error were evaluated by testing the measured recovery of a reference source of ultra-high-purity $\mathrm{CH}_{4}$ standard released at calibrated rates at specific points in the chambers to test the accuracy of specific components of the measurement system. The tested sources of error were analyzer error, ducting efficiency (from chambers to analyzers, including measurements of airflow), and mixing of air in chamber. Of these, ducting and airflow measurement were the largest source of variation in $\mathrm{CH}_{4}$ standard recovery within and between $\mathrm{RC}$ and research facilities $(1.3,15.3$, and $3.4 \%$ variation for analyzers, ducting/flow, and air mixing in chamber, respectively). Chambers need to be routinely calibrated and demonstrate gas recovery rates of approximately $100 \%$ both before and after each experimental deployment, as highlighted recently by Gerrits et al. (2018).

As well as these issues, several other common but often overlooked issues can influence $\mathrm{CH}_{4}$ yield measurements made using RC. Animals in RC must have stable daily feed intake. Moate et al. (2012) showed that, for a dairy cow in RC, approximately $30 \%$ of today's $\mathrm{CH}_{4}$ emissions are a result of yesterday's DMI. It is commonly observed that dairy cows may slightly reduce their DMI on the first day they enter a respiration chamber (data from the first day are normally excluded from the analysis). Thus, day-to-day variation in total DMI can cause an error in estimated $\mathrm{CH}_{4}$ yield of up to 3\% (Moate et al., 2012). If RC are fitted with air locks for entry and feeding, disruption to measurements is minimized, the entry and presence of staff in the RC can be accounted for (see Reynolds and Tyrrell, 2000), and measurements can be obtained without interruption for successive 24 -h periods (Flatt et al., 1958; Tyrrell et al., 1979). However, many modern RC are constructed such that the chamber doors must be opened for approximately $30 \mathrm{~min}$ at least twice per day to enable milking and cleaning. With exclusion of these time slots, $\mathrm{CH}_{4}$ measurements from a specific chamber may cover approximately $23 \mathrm{~h} / \mathrm{d}$. There does not appear to be an internationally agreed protocol for filling the total 1-h "gap" in missing $\mathrm{CH}_{4}$ measurements. Interpolation may be used for this purpose but what approximation should be used for the missing data? This would not be a problem if the rate of $\mathrm{CH}_{4}$ emissions were constant over the course of a day, but with dairy cows, there is often considerable hour-to-hour variation in rate of $\mathrm{CH}_{4}$ production, with the peak hourly rate of $\mathrm{CH}_{4}$ emission being more than 3 times the minimum hourly rate of $\mathrm{CH}_{4}$ emission. Depending on feeding (immediately upon entrance or just before leaving the chamber), the most accurate estimate of $\mathrm{CH}_{4}$ production rates during the two 30-min gap periods is the average of the $\mathrm{CH}_{4}$ production immediately preceding and after each opening, or the $\mathrm{CH}_{4}$ production rate immediately preceding each opening of the chamber. However, the most common practice is to use the mean rate of $\mathrm{CH}_{4}$ production as measured during the $23 \mathrm{~h}$ for which data are available. The latter interpolation method can result in an overestimation of $\mathrm{CH}_{4}$ emission and hence $\mathrm{CH}_{4}$ yield by approximately $2 \%$ (P. J. Moate, unpublished data). In contrast, van Gastelen et al. (2017) established a very small difference of $0.1 \%$ in daily $\mathrm{CH}_{4}$ emission rate when comparing discarding 
HRISTOV ET AL.

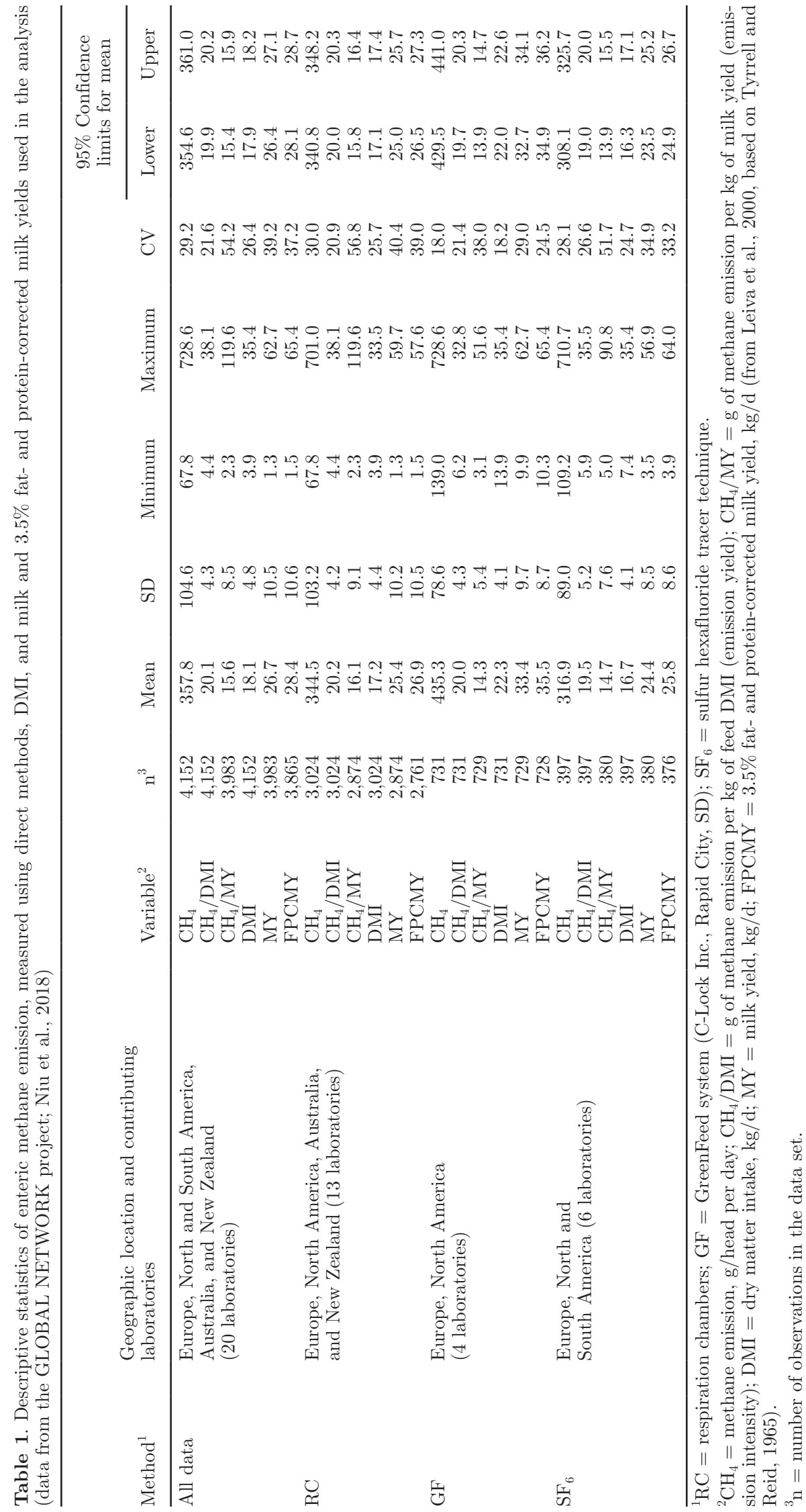


(and interpolating between last time point before opening and first time point after closing the chamber) with not discarding the data from these time slots.

\section{The $S F_{6}$ Technique}

Another widely used technique to measure enteric $\mathrm{CH}_{4}$ emissions is the $\mathrm{SF}_{6}$ tracer method (Zimmerman, 1993; Johnson et al., 1994). Variability with the $\mathrm{SF}_{6}$ technique has been notoriously high (Pinares-Patiño and Clark, 2008; Pinares-Patiño et al., 2011), but the modifications by Deighton et al. (2014) addressed the most important sources of error, and the modified technique produced $\mathrm{CH}_{4}$ measurements with accuracy similar to measurements using RC. Part of the variation with $\mathrm{SF}_{6}$ seems intrinsic to the technique because the estimated $\mathrm{CH}_{4}$ emission rate appears sensitive to factors that affect the proportions of exhaled and eructated air in the air samples collected and distance of the sampling point from to the mouth/nostrils (Berends et al., 2014), which is not an issue with RC. Several important conditions must be met to reduce variability in the $\mathrm{CH}_{4}$ measurement data when the $\mathrm{SF}_{6}$ technique is used. These include (1) high and known release rate of $\mathrm{SF}_{6}$ from the permeation tube, (2) at least 5 (depending on day-today variation in emission rates; Arbre et al., 2016) consecutive measurement days, and (3) low concentrations of $\mathrm{SF}_{6}$ and $\mathrm{CH}_{4}$ in the background air (i.e., using the technique in enclosed barns is not recommended, unless there is adequate ventilation throughout the measurement period; Dorich et al., 2015; Hristov et al., 2016). Even with adequate ventilation, samples of background air concentrations should always be included to correct the measurements obtained. In this regard, the method of obtaining background concentrations is important and should be as representative as possible of the background air in which the measurements are being obtained. A suitable approach is to include animals in the trial that are sampled in the same way as the other animals in the study but are not given an $\mathrm{SF}_{6}$ permeation tube. Other concerns addressed by the studies of Deighton et al. (2014) include variation in release rate of permeation tubes over time (months) after calibration and variation in sampling rate over time (hours) during the sampling day, both of which can introduce bias in estimates obtained. Variation in release rate can be accounted for in part by using Michaelis-Menten kinetics to estimate the decay in release rate over time, rather than first-order kinetics (Deighton et al., 2014) if measurements are obtained more than $60 \mathrm{~d}$ after calibration of permeation tubes. Deighton et al. (2014) also showed that bias due to variation in sampling rate over the course of a 24-h sampling period is markedly reduced when orifice plate flow controllers, rather than capillary tubes, are used to obtain air samples. Because of diurnal changes in $\mathrm{CH}_{4}$ emission over the course of each day, sampling for less than $24 \mathrm{~h}$ is not appropriate for estimates of daily rate of $\mathrm{CH}_{4}$ emission. When these conditions and considerations are addressed, the $\mathrm{SF}_{6}$ tracer technique can produce accurate $\mathrm{CH}_{4}$ emission data from a large group of animals. In a review of $\mathrm{CH}_{4}$ emission techniques, Hammond et al. (2016a) reported that, in 5 studies comparing $\mathrm{CH}_{4}$ emissions from dairy cows obtained using $\mathrm{RC}$ and $\mathrm{SF}_{6}$ (simultaneously in 2 studies), measurements of $\mathrm{CH}_{4}$ emission were not significantly different in 4 studies and were different in 1 study (422 vs. $469 \mathrm{~g} / \mathrm{d}$ ). Detailed guidelines for using the $\mathrm{SF}_{6}$ technique were published by an international panel of experts (Berndt et al., 2014).

\section{The GreenFeed System}

A more recent technique for direct measurement of enteric $\mathrm{CH}_{4}$ emissions is the automated head-chamber system GreenFeed, which was developed for spot sampling of exhaled and eructated gases (Zimmerman and Zimmerman, 2012). When properly used (Hristov et al., 2015a), GF can be a reliable technique for measuring enteric $\mathrm{CH}_{4}$ emissions from ruminant animals (Dorich et al., 2015; Hammond et al., 2016a,b; Hristov et al., 2016). An important prerequisite for decreasing uncertainty of the measurement when using GF is that all animals visit the unit at times that enable estimation of the diurnal pattern of $\mathrm{CH}_{4}$ emission over successive 24-h periods. Methane emissions have a clear diurnal pattern related to the pattern of feed intake (usually lower at night; Brask et al., 2015; Hammond et al., 2016a); therefore, for accurate daily emission estimates, animal visits need to be distributed appropriately over the 24-h feeding cycle. The number and timing of visits to GF will vary depending on the type of animal, the diet fed, and the level of DMI (Hammond et al., 2016a,b). Reliable results with GF can be obtained when the number and timing of animal visits are controlled by the investigator, which is easily achievable in a tiestall barn situation (Branco et al., 2015; Hristov et al., 2015b; Dittmann et al., 2016). Alternatively, measurements have to take place over a prolonged period (up to 3 to $5 \mathrm{wk}$, depending on the study objectives; Arbre et al., 2016; Renand and Maupetit, 2016; Arthur et al., 2017). Obtaining measurements at specific time points from each animal on a study over a series of days increases precision and, as a result, can provide an accurate determination of treatment effects on $\mathrm{CH}_{4}$ emission. However, the measurements obtained are not necessarily accurate estimates of daily emission rate, if the timing of measurements does not adequately account for the diurnal pattern of emission (Doreau 
et al., 2018). For studies in which groups of animals are provided access to a GF unit (or units), timing of use can be influenced by programming the unit to only provide feed to animals at specific intervals, which encourages the animals to visit the unit at varied times throughout successive days. Nevertheless, in practice, the number of visits tends to be higher at specific times of the day (e.g., Hammond et al., 2015, 2016a,b) and may be influenced by the type of diet fed.

A recent evaluation of a large number of estimates of $\mathrm{CH}_{4}$ emission rate $(\mathrm{g} / \mathrm{d})$ from 2 studies in growing beef cattle (Arthur et al., 2017) examined the number of observations (spot measurements) required to reliably estimate daily emission rate using GF, based on the reduction in variance observed with increasing number of observations. The authors found that as long as measurements were of sufficient duration (at least $3 \mathrm{~min}$ ), 30 observations were sufficient to obtain reliable $\mathrm{CH}_{4}$ emission data, regardless of how many times per day the measurements were obtained (on average 4.4 per day in one study and 1.3 per day in another), although the problem of unbalanced spread of visits over a $24-\mathrm{h}$ period in view of diurnal $\mathrm{CH}_{4}$ production patterns is not necessarily solved. These results emphasize the need for sufficient numbers of GF measurements per experimental unit (animal on a given treatment) for studies where animals are allowed voluntary access to the equipment. Another potential source of error in outdoor use is the effect of wind on the capture efficiency of the GF unit, which is used in the calculation of $\mathrm{CH}_{4}$ emission rate for each measurement. Variation in wind speed and direction can affect measurements (Huhtanen et al., 2015a); thus, it is recommended that units used outdoors be fitted with anemometers to record wind speed during measurements so attempts can be made to correct measurements for the effects of wind. Measurements obtained using GF, similar to those obtained using the $\mathrm{SF}_{6}$ technique, do not include $\mathrm{CH}_{4}$ emissions from the rectum, but these emissions are typically small (approximately $1-3 \%$, as measured or estimated by Murray et al., 1976 and Muñoz et al., 2012, respectively).

Overall, both $\mathrm{GF}$ and $\mathrm{SF}_{6}$ are established techniques and can produce accurate estimates for enteric $\mathrm{CH}_{4}$ emission when properly used and calibrated. Emphasis on further improvement of the methodology and experimental set-up (Deighton et al., 2014; Hristov et al., 2015a) will increase the accuracy of these techniques. Direct comparisons of GF and $\mathrm{SF}_{6}$ with $\mathrm{RC}$ have shown acceptable agreement in some studies (e.g., Grainger et al., 2007; Muñoz et al., 2012; Deighton et al., 2014; Hammond et al., 2016b; Velazco et al., 2016; Jonker et al., 2016; Huhtanen et al., 2018; Alemu et al., 2017; Rischewski et al., 2017) but not in others (e.g., Pin-

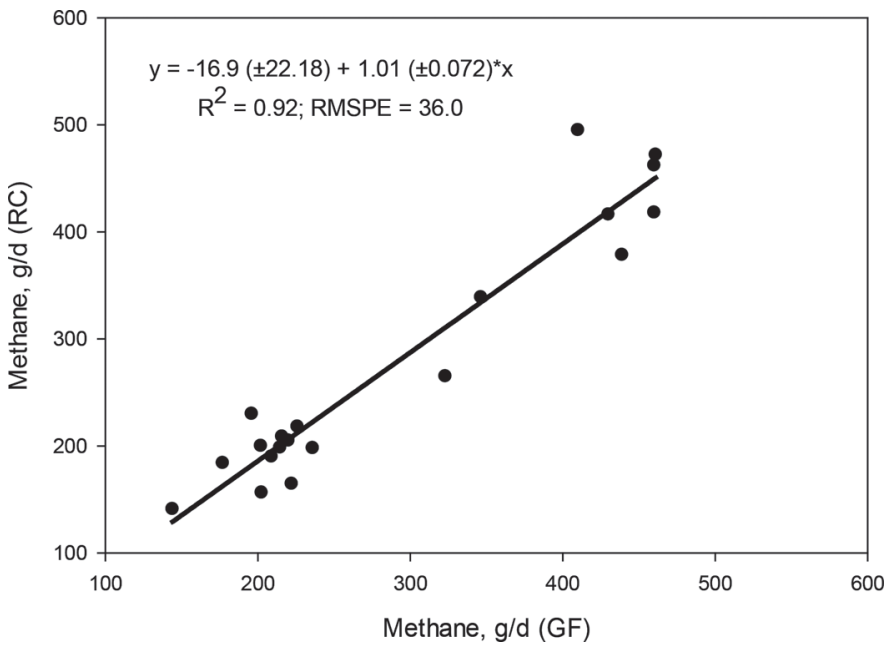

Figure 1. Relationship between enteric methane emission measured using GreenFeed (GF; C-Lock Inc., Rapid City, SD) and that measured using respiration chambers $(\mathrm{RC})$ in 6 studies $(\mathrm{n}=20$; Hammond et al., 2015, 2016b; Jonker et al., 2016; Alemu et al., 2017; Rischewski et al., 2017) in which the 2 techniques were directly compared. RMSPE $=$ root mean squared prediction error.

ares-Patiño et al., 2011; Hammond et al., 2015). The modified $\mathrm{SF}_{6}$ technique, as proposed by Deighton et al. (2014), showed good agreement with $\mathrm{RC} ; \mathrm{CH}_{4}$ yield was not different between $\mathrm{SF}_{6}$ and $\mathrm{RC}$, and the betweenanimal $\mathrm{CV}$ were similar between the 2 techniques $(6.5$ and $7.5 \%$, respectively). A recent meta-analysis showed a strong relationship $\left(\mathrm{R}^{2}=0.92\right)$ between $\mathrm{CH}_{4}$ emissions measured in RC and by GF used in the same experiment (Figure 1; Huhtanen et al., 2018). Sources of uncertainties with both techniques have been discussed above. To reduce variability in data generated by $\mathrm{SF}_{6}$ or GF, researchers have to strictly follow recommended procedures or adjust these procedures to their specific experimental conditions when necessary.

\section{Indirect Methods}

Indirect approaches have been proposed and used to measure enteric $\mathrm{CH}_{4}$ emissions in livestock. Usually, these methods are associated with lower accuracy and greater uncertainty in the emission data than the direct methods described above. One approach used estimated $\mathrm{CO}_{2}$ emission and measured $\mathrm{CO}_{2}: \mathrm{CH}_{4}$ ratio in exhaled air to estimate $\mathrm{CH}_{4}$ emission (Madsen et al., 2010). Changes in digestive and metabolic activities (even at the same level of feed intake), differences in feed efficiency, as well as variation in ruminal fermentation can all influence the amount of $\mathrm{CO}_{2}$ produced by the animal and thus affect the predicted $\mathrm{CH}_{4}$ emission (Huhtanen et al., 2015a). The $\mathrm{CO}_{2}: \mathrm{CH}_{4}$ ratio technique is comparable to the $\mathrm{SF}_{6}$ technique in some ways, but 
it is usually based on "spot" measurements of breath $\mathrm{CH}_{4}$ concentration, rather than integrated measurements over $24 \mathrm{~h}$, and the emission rate of the "tracer" gas $\left(\mathrm{CO}_{2}\right)$ is estimated, rather than relying on emission from a calibrated delivery device in the rumen, as with the $\mathrm{SF}_{6}$ technique. Haque et al. (2017) evaluated $\mathrm{CH}_{4}$ production calculated using observed $\mathrm{CO}_{2}$ production in $\mathrm{RC}$ versus using $\mathrm{CO}_{2}$ production calculated based on the heat production method of Madsen et al. (2010). In that evaluation, $\mathrm{CH}_{4}$ production estimated using calculated $\mathrm{CO}_{2}$ production resulted in smaller differences and changed the significance of treatment effects between diets compared with using the actual observed $\mathrm{CO}_{2}$ production.

Another indirect method proposed by Garnsworthy et al. (2012) relies on estimating $\mathrm{CH}_{4}$ emission during an eructation event and the frequency of eructation during a measurement period - the "sniffer" method. A feature of the method is that hundreds of repeated measurements can be made at little additional cost over prolonged periods. In 2 experiments with lactating cows, however, Huhtanen et al. (2015a) found larger variability with the sniffer method and no relationship to emissions measured using GF. Distance from the sampling inlet had a strong influence on measured gas concentration in a laboratory study and, in an animal study, the measured $\mathrm{CH}_{4}$ concentration was strongly related to head position (Huhtanen et al., 2015a). In addition, head position was a highly repeatable characteristic precluding that an increased number of observations could solve the problem. Another recent study concluded that the capability of the sniffer method to adequately measure and rank $\mathrm{CH}_{4}$ emission rates among dairy cows is highly uncertain and requires further investigation into the sources of variation (Wu et al., 2018).

Another indirect technique uses a laser $\mathrm{CH}_{4}$ detector to measure $\mathrm{CH}_{4}$ mixing ratio in the air between the laser device and the animal (usually 1 to $3 \mathrm{~m}$ ). The method allows $\mathrm{CH}_{4}$ measurements in on-farm conditions and from a large number of animals; however, comparative studies found a positive but weak relationship between the laser method and RC measurements (Chagunda et al., 2013; Ricci et al., 2014), although the device was found to accurately record variations in $\mathrm{CH}_{4}$ in spent air of RC (Sorg et al., 2017). Environmental factors such as temperature, wind velocity (particularly important for grazing conditions), proximity of other animals, humidity, and others can affect the accuracy of the measurements. Further critical evaluation of these indirect methods has been provided in Hammond et al. (2016a), but as the methods are "indirect," they rely on assumed relationships between concentrations of $\mathrm{CH}_{4}$ in breath and other parameters and as such are subject to greater variance and uncertainty than direct measures of $\mathrm{CH}_{4}$ emission rate.

\section{UNCERTAINTIES IN PREDICTING ENTERIC METHANE EMISSIONS}

\section{Relationship of DMI with $\mathrm{CH}_{4}$ Emission and Prediction of DMI}

Dry matter intake is an important factor in enteric $\mathrm{CH}_{4}$ prediction models. Models predicting DMI can be used in conjunction with emission factors to estimate enteric $\mathrm{CH}_{4}$ emissions in a Tier 2 approach (which is based on country-specific emission factors and other data). Appuhamy et al. (2016) evaluated 40 prediction equations using data that included measured DMI and feed quality attributes. The best performing models in each region (North America, Europe, and Australia and New Zealand) were then re-evaluated using predicted DMI and compared with estimates that used measured DMI. Appuhamy et al. (2016) reported that models using estimated DMI predicted enteric $\mathrm{CH}_{4}$ emissions as accurately as the measured data if DMI could be estimated with reasonable accuracy. Thus, enteric $\mathrm{CH}_{4}$ emissions could be predicted well without DMI measurements for North America. For Europe, using estimated DMI rather than observed DMI resulted in satisfactory $\mathrm{CH}_{4}$ emissions prediction. For Australia and New Zealand, $\mathrm{CH}_{4}$ emissions could not be estimated well without actual DMI measurements. These differences were likely due to the models used. The DMI prediction model was developed based on North American data and may not work well with diets that have greater forage proportion, including cattle on pasture. In the GLOBAL NETWORK database of individual dairy cow data (Niu et al., 2018), $\mathrm{CH}_{4}$ prediction equations with a greater number of independent variables performed best and had lower root mean squared prediction error (RMSPE) as a percentage of the mean observed value (14.7 to $19.8 \%$ ). However, less complex models requiring only DMI had predictive ability comparable to those of the more complex models $(\mathrm{RMSPE}=15.2$ to $21.4 \%)$. This indicates that DMI alone may be sufficient to predict enteric $\mathrm{CH}_{4}$ emissions for inventory purposes (as discussed in Hristov et al., 2017). The coefficient of determination for the relationship of measured $\mathrm{CH}_{4}$ emissions with DMI, however, can be highly variable and may be influenced by several factors, including $\mathrm{CH}_{4}$ measurement technique.

The relationships of measured $\mathrm{CH}_{4}$ production and DMI (absolute or expressed on a BW basis) and NDF intake (NDFI) in the GLOBAL NETWORK dairy database (Niu et al., 2018) were investigated using the MIXED and REG procedures of SAS (version 9.4; SAS 
Institute Inc., Cary, NC). Table 2 summarizes the results of these analyses. The linear relationship of DMI and $\mathrm{CH}_{4}$ production was moderately strong $\left(\mathrm{R}^{2}=0.58\right)$ for the RC data (Figure 2, RC) and similar to the relationship for the entire data set $\left(\mathrm{R}^{2}=0.63\right.$; Figure 2 , all data) but was very weak for $\mathrm{GF}\left(\mathrm{R}^{2}=0.05\right.$; Figure 2, $\mathrm{GF})$ and low for the $\mathrm{SF}_{6}$ technique $\left(\mathrm{R}^{2}=0.27\right.$; Figure $\left.2, \mathrm{SF}_{6}\right)$; nonlinear models did not improve the relationship (data not shown). The estimated slopes indicate a much larger incremental yield in $\mathrm{CH}_{4}$ with increasing $\mathrm{DMI}$ for RC than for $\mathrm{GF}$ and $\mathrm{SF}_{6}(16.12 \pm 0.299,7.53$ \pm 0.775 , and $5.87 \pm 1.373 \mathrm{~g}$ of $\mathrm{CH}_{4} / \mathrm{kg}$ of DMI, respectively). The prediction error was also lower for RC than for GF or $\mathrm{SF}_{6}$. Similarly, relationships between DMI as a fraction of BW, NDFI, or milk yield or ECM yield and $\mathrm{CH}_{4}$ were stronger for $\mathrm{RC}$ data than for $\mathrm{GF}$ or $\mathrm{SF}_{6}$. This can be partially explained by the wider range of DMI data in the RC subset compared with that of GF or $\mathrm{SF}_{6}$. The relationship of $\mathrm{CH}_{4}$ emissions and DMI is usually strong with wider ranges of DMI (Hristov et al., 2013; Charmley et al., 2016) and weak when the range of DMI is narrower (Hristov et al., 2015b). The meta-analysis by Charmley et al. (2016) was on a large Australian data set (1,033 observations) including both dairy and beef cattle data and clearly showed that relationship between DMI and $\mathrm{CH}_{4}$ emissions was strong $\left(R^{2}=0.92\right)$ and the intercept was close to zero when DMI range was large (from about 2 to $28 \mathrm{~kg} / \mathrm{d}$ in their analysis). If RC data in the current analysis were restricted to DMI $>15 \mathrm{~kg} / \mathrm{d}, \mathrm{R}^{2}$ for the relationship with DMI decreased to 0.41 and root mean squared error increased to 68.2 (data not shown).

A moderate relationship between DMI and $\mathrm{CH}_{4}$ emissions has been established for both $\mathrm{GF}$ and $\mathrm{SF}_{6}$ techniques. In a meta-analysis of dairy cow studies by Grainger et al. (2007), the relationship between DMI and $\mathrm{CH}_{4}$ emission as measured by the $\mathrm{SF}_{6}$ technique was $\mathrm{R}^{2}=0.56$ and was better than the relationship between DMI and $\mathrm{CH}_{4}$ emission for $\mathrm{RC}\left(\mathrm{R}^{2}=0.39\right)$. The authors noted that in only $22 \%$ of the studies was the

Table 2. Relationships of enteric methane emission (g/head per day), measured using direct methods, and DM or NDF intake and milk and $3.5 \%$ fat- and protein-corrected milk yields in dairy cows (data from the GLOBAL NETWORK project; Niu et al., 2018)

\begin{tabular}{|c|c|c|c|c|c|c|c|c|c|}
\hline Method $^{1}$ & Variable $^{2}$ & $\mathrm{n}^{3}$ & \multicolumn{2}{|c|}{ Intercept $^{4}$} & \multicolumn{2}{|c|}{ Slope ${ }^{4}$} & \multicolumn{3}{|c|}{$\mathrm{REG}^{5}$} \\
\hline \multirow[t]{4}{*}{ All data } & DMI & 4,152 & 110.9 & 6.91 & 13.55 & 0.294 & 49.4 & 0.63 & 13.9 \\
\hline & NDFI & 3,729 & 157.8 & 7.43 & 31.23 & 0.783 & 76.3 & 0.46 & 21.0 \\
\hline & NDFI/BW & 3,604 & 256.2 & 9.03 & 94.52 & 5.277 & 95.0 & 0.15 & 26.2 \\
\hline & MY & 3,983 & 293.0 & 7.53 & 2.54 & 0.157 & 90.9 & 0.23 & 25.1 \\
\hline & $\mathrm{DMI} / \mathrm{BW}$ & 2,924 & 180.7 & 9.60 & 56.41 & 2.402 & 83.6 & 0.34 & 24.2 \\
\hline & NDFI & 2,629 & 126.2 & 7.81 & 35.69 & 0.807 & 69.9 & 0.53 & 20.0 \\
\hline & NDFI/BW & 2,563 & 226.1 & 9.66 & 116.3 & 5.95 & 88.4 & 0.25 & 25.2 \\
\hline & MY & 2,874 & 275.6 & 8.14 & 2.92 & 0.177 & 89.3 & 0.25 & 25.6 \\
\hline & FPCMY & 2,761 & 243.4 & 7.86 & 3.98 & 0.177 & 84.3 & 0.34 & 24.2 \\
\hline \multirow[t]{2}{*}{ GF } & DMI & 731 & 265.8 & 22.17 & 7.53 & 0.775 & 76.5 & 0.05 & 17.6 \\
\hline & DMI/BW & 680 & 396.9 & 23.96 & 12.91 & 5.400 & 78.3 & 0.00 & 18.0 \\
\hline & $\mathrm{DMI} / \mathrm{BW}$ & 389 & 288.8 & 30.20 & 16.58 & 7.32 & 86.7 & 0.04 & 27.5 \\
\hline & NDFI & 397 & 243.7 & 29.31 & 14.87 & 3.32 & 85.6 & 0.08 & 27.0 \\
\hline & $\mathrm{NDFI} / \mathrm{BW}$ & 389 & 287.1 & 29.21 & 45.27 & 16.07 & 88.5 & 0.00 & 28.1 \\
\hline & MY & 380 & 316.0 & 28.66 & 1.34 & 0.805 & 81.4 & 0.14 & 25.3 \\
\hline & FPCMY & 376 & 291.1 & 27.73 & 2.16 & 0.757 & 80.5 & 0.17 & 25.1 \\
\hline
\end{tabular}

\footnotetext{
${ }^{1}$ All data $=$ all data in the GLOBAL NETWORK project dairy data set; $\mathrm{RC}=$ data from studies using respiration chambers only; GF $=$ data from studies using the GreenFeed system (C-Lock Inc., Rapid City, SD) only; $\mathrm{SF}_{6}=$ data from studies using the sulfur hexafluoride tracer technique only.

${ }^{2} \mathrm{DMI}=$ dry matter intake, $\mathrm{kg} / \mathrm{d}$; NDFI = neutral-detergent fiber intake, $\mathrm{kg} / \mathrm{d}$; BW = body weight, $\mathrm{kg}$; DMI (or NDFI) $/ \mathrm{BW}=\mathrm{DMI}$ or NDFI as $\%$ of BW; $\mathrm{MY}=$ milk yield, $\mathrm{kg} / \mathrm{d} ; \mathrm{FPCMY}=3.5 \%$ fat- and protein-corrected milk yield, $\mathrm{kg} / \mathrm{d}$ (from Leiva et al., 2000, based on Tyrrell and Reid, 1965).

${ }^{3} \mathrm{n}=$ number of observations in the data set.

${ }^{4}$ Mixed regression model analysis; all $P$-values $<0.001$.

${ }^{5} \mathrm{REG}=$ fit statistics from a fixed regression model; RMSE $=$ root mean squared error.
} 

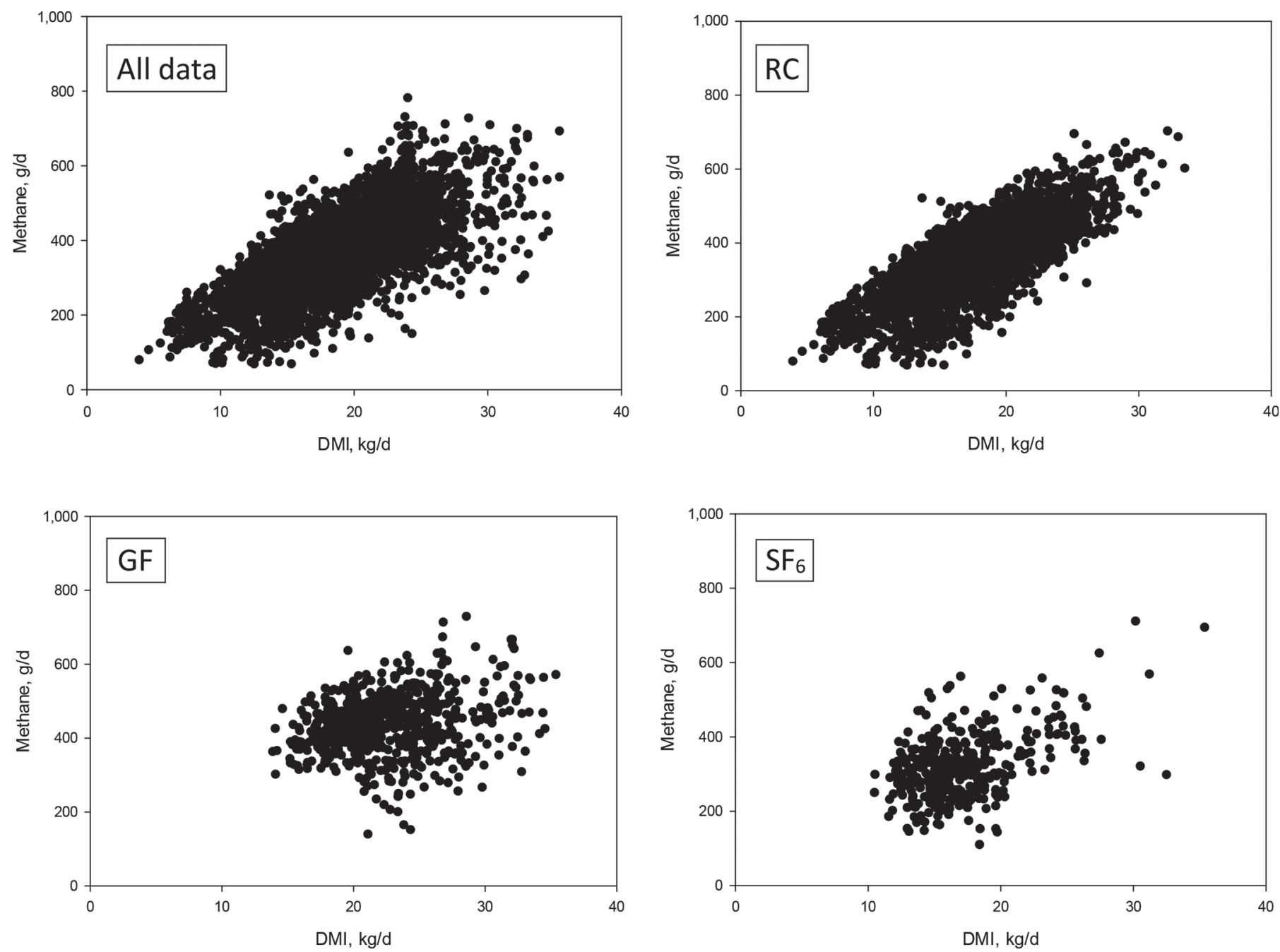

Figure 2. Relationship of methane emission (g/head per day) and DMI (kg/d) data from the GLOBAL NETWORK database (Niu et al., 2018); All data = all data from the database, $\mathrm{RC}=$ data from studies in which methane emission was measured in respiration chambers, GF $=$ data from studies in which methane emission was measured using GreenFeed (C-Lock Inc., Rapid City, SD), and SF ${ }_{6}=$ data $_{\text {from studies in }}$ which methane emission was measured using the sulfur hexafluoride technique. For more details, see text and Tables 1 and 2.

DMI of the cows $>20 \mathrm{~kg} / \mathrm{d}$; more data are needed to establish a reliable relationship for greater DMI. A moderately strong relationship $\left(\mathrm{R}^{2}=0.44\right)$ of $\mathrm{DMI}$ and $\mathrm{CH}_{4}$ emissions was demonstrated for $\mathrm{GF}$ in a beef data set (445 observations; DMI ranged from 3.6 to $19.1 \mathrm{~kg} / \mathrm{d}$ ) by Bird-Gardiner et al. (2017). In an experiment with dairy cows consuming around $28 \mathrm{~kg}$ of $\mathrm{DM} / \mathrm{d}$, however, the relationship of DMI with $\mathrm{CH}_{4}$ emissions measured with GF or the $\mathrm{SF}_{6}$ technique was relatively weak: $\mathrm{R}^{2}=$ 0.47 and 0.08 , respectively (Hristov et al., 2015b). The absence of a strong relationship between DMI and $\mathrm{CH}_{4}$ emissions observed in the current analysis for both GF and $\mathrm{SF}_{6}$, compared with the relationship for $\mathrm{RC}$ (Table 2 and Figure 2), is difficult to explain but reflects, in part, the variation associated with implementation the former techniques, as discussed earlier.
Most models developed to predict enteric $\mathrm{CH}_{4}$ emissions usually include either DMI or some form of feed/ nutrient intake; therefore, as pointed out earlier, accurate prediction of DMI is important for accurate prediction of $\mathrm{CH}_{4}$ emissions and yield. The current dairy NRC (2001) model predicts DMI based on the cow's metabolic BW, FCM yield, and stage of lactation. Dry matter intake prediction models for other categories of dairy cattle or beef cattle involve a variable for $\mathrm{BW}$ (metabolic BW or initial shrunk $\mathrm{BW}$ ) and $\mathrm{NE}_{\mathrm{M}}$ concentration (NRC 2000, 2001, 2016). Numerous DMI prediction models have been proposed and evaluated (Ingvartsen, 1994; Mertens, 1995). An in-depth review of these models is outside the scope of this analysis and the examples given here are to illustrate the variable approaches (e.g., feed composition; animal factors 
such as BW, parity, and lactation stage; physiological mechanisms; genomic prediction of DMI) undertaken to understand the factors important in regulating DMI in dairy cows.

Although it is generally agreed that DMI is the most important factor influencing $\mathrm{CH}_{4}$ production, the general nature of this relationship remains undetermined. In the original equation proposed by Blaxter and Clapperton (1965), the relationship was curvilinear based on feeding level. More recently, Knapp et al. (2014) also proposed a curvilinear relation between DMI and $\mathrm{CH}_{4}$ production, with $\mathrm{CH}_{4}$ yield decreasing at high DMI. In dairy cows, very high DMI is usually only achieved with diets containing a relatively high proportion of concentrate feeds, and high concentrate diets are known to decrease $\mathrm{CH}_{4}$ production (Blaxter and Clapperton, 1965). When the diet of cattle contains less than $30 \%$ concentrate, the relationship between DMI and $\mathrm{CH}_{4}$ production has been shown to be linear, even to intakes up to $27 \mathrm{~kg}$ of DM/d (Charmley et al., 2016). A metaanalysis by Hristov et al. (2004) indicated that dietary concentrations of protein and carbohydrate fractions were important variables in predicting DMI in lactating dairy cows (and DMI was the dominant factor for estimating milk and milk protein yield). Shah and Murphy (2006) proposed an exponential DMI model based on lactation asymptotic maximum DMI and DIM. Zom et al. (2012) proposed a DMI prediction model based on estimated (from parity number, DIM, and days pregnant) feed intake capacity and a feed-specific satiety value, based on feed chemical composition and digestibility. The latter model and 4 other models (NRC, 2001 and 3 European models) were evaluated by Jensen et al. (2015). The models predicted DMI with various accuracies (RMSPE of 1.2 to $3.2 \mathrm{~kg} / \mathrm{d}$ ); best prediction was by a complex model involving BW, parity, DIM, milk yield, and dietary (forage) $\mathrm{NE}_{\mathrm{L}}$. An analysis of DMI prediction by 5 feeding systems yielded prediction errors of 1.6 to $3.2 \mathrm{~kg} / \mathrm{d}$ (Krizsan et al., 2014). Appuhamy et al. (2018) evaluated the comprehensive (IPCC-CMP) and simplified (IPCC-SMP) IPCC models (IPCC, 2006), the modified Cornell Net Carbohydrate and Protein System model (CNCPS; Fox et al., 1992 as modified by Arnerdal, 2005), and the NRC (2001) models to predict DMI using an independent data set. The modified CNCPS, relying on BW and FCM yield, more accurately predicted DMI (RMSPE = $14.1 \%$ ) than the NRC (RMSPE $=19.4 \%)$, IPCC-SMP $(\mathrm{RMSPE}=16.9 \%)$, or IPCC-CMP $(\mathrm{RMSPE}=23.4 \%)$ models. Overall, the results by Appuhamy et al. (2018) demonstrated that DMI can be predicted successfully using information such as milk yield and milk fat content (routinely available on dairy farms), which could therefore be used to estimate enteric $\mathrm{CH}_{4}$ emissions.

\section{Prediction of $\mathrm{CH}_{4}$ Emissions}

Prediction models have been widely used to estimate variation in $\mathrm{CH}_{4}$ emissions for a variety of purposes (Kebreab et al., 2006). Many countries and regions of the world have set targets for the reduction of GHG emissions including $\mathrm{CH}_{4}$. For example, California recently passed legislation mandating a reduction in the statewide emission of $\mathrm{CH}_{4}$ by $40 \%$ below the 2013 levels by 2030 (State of California, 2017). Assessment of baseline emission in 2013 was determined using mathematical models, particularly those recommended by the IPCC (2006) and used in almost all national inventory protocols. Therefore, the accuracy of the model used is important in setting and assessing achievable targets. As existing models are based on limited databases, new and more-accurate models are required to establish the baseline for assessing any reduction in emissions or estimating global $\mathrm{CH}_{4}$ emissions attributable to enteric fermentation. Where data sets used for $\mathrm{CH}_{4}$ emission prediction model development are composed of data from multiple sources (e.g., different research groups and multiple studies) such as, for example, the GLOBAL NETWORK project, the effect of both research groups and studies should be incorporated in the model (Niu et al., 2018). In addition, if more than one $\mathrm{CH}_{4}$ measurement technique was used by the same research group, the within-group variation from different techniques should also be considered.

\section{Types of Models Used to Predict Enteric $\mathrm{CH}_{4}$ Emissions}

Enteric $\mathrm{CH}_{4}$ emission predictions are obtained using different types of models. These range from simple emission factors (e.g., IPCC, 2006; Tier 1) and empirical models (e.g., Ramin and Huhtanen, 2013) to more detailed mechanistic models (e.g., Baldwin, 1995; Mills et al., 2001). Some models have been developed specifically to predict enteric $\mathrm{CH}_{4}$ emissions from feed intake and other diet attributes (such as, for example, NDF and ether extract concentrations; e.g., Moraes et al., 2014); others have been modified or adapted to calculate emissions from ruminal fermentation kinetics (e.g., Alemu et al., 2011). Models estimating enteric $\mathrm{CH}_{4}$ emissions can be broadly characterized as being empirical or mechanistic. Empirical models are based on mathematical or statistical associations of diet intake and composition and other animal factors with enteric $\mathrm{CH}_{4}$ emissions. Mechanistic models are based on biochemical, metabolic, and physiological principles and attempt to simulate enteric $\mathrm{CH}_{4}$ emissions on the basis of a mathematical description of fermentation biochemistry. 
Empirical Models. Empirical models to predict $\mathrm{CH}_{4}$ emissions have been developed since the 1930s (Kriss, 1931) and there are many models in this category found in the scientific literature. For example, Appuhamy et al. (2016) listed 40 such models that were developed in North America, Europe, Australia, and New Zealand. Because enteric $\mathrm{CH}_{4}$ emissions are strongly related to feed intake, all models include a measure of intake, such as DMI, gross energy (GE) intake (GEI), ME intake, or NDFI. However, feed intake of individual animals is not routinely measured under commercial farm operations, and thus there may be a need to develop equations that do not require feed intake measures or estimates. The advantage of empirical models is that they can be constructed relatively easily from observed data and do not require a large number of inputs from the user. The most commonly used inputs for empirical model development are summarized in Figure 3. However, because enteric $\mathrm{CH}_{4}$ emissions are affected by several factors other than feed intake, prediction ability may be compromised if the sample is not large enough and a representative population is not sampled. It is a challenge to represent $\mathrm{CH}_{4}$-mitigating additives, including nitrate (Olijhoek et al., 2016) and 3-nitrooxypropanol (Hristov et al., 2015b) in existing empirical models. Empirical models are currently used to estimate the contribution of the livestock industry to GHG emissions, particularly enteric $\mathrm{CH}_{4}$ emissions nationally and globally. For example, several countries, including the United States, use the following IPCC Tier 2 equation to determine enteric $\mathrm{CH}_{4}$ emissions:

$$
\mathrm{CH}_{4}=\mathrm{Y}_{\mathrm{m}} \times \mathrm{GEI} \text {, }
$$

where $\mathrm{CH}_{4}$ is enteric $\mathrm{CH}_{4}$ emission in $\mathrm{MJ} /$ head per day, and $\mathrm{Y}_{\mathrm{m}}=\mathrm{CH}_{4}$ conversion factor defined as percentage of GEI (MJ/head per day). This needs 2 kinds of inputs: feed DMI and the GE concentration of feeds. Although GE can be determined by bomb calorimetry, this analytical method is tedious and requires some expertise. Most forages and grains have a GE of approximately $18.4 \mathrm{MJ} / \mathrm{kg}$ of $\mathrm{DM}$, but protein-rich or high-fat feeds such as oilseeds have a much greater GE as fats contain approximately $37 \mathrm{MJ} / \mathrm{kg}$ of $\mathrm{DM}$ and protein contains approximately $24 \mathrm{MJ} / \mathrm{kg}$ of $\mathrm{DM}$, whereas feeds rich in minerals (ash) have a lower GE content. However, IPCC (1997) guidelines estimate GEI through determination of net energy requirements for body functions, which are then connected to DMI using estimated energy digestibility and digestible energy utilization efficiency. The steps involved in determining GEI and $\mathrm{Y}_{\mathrm{m}}$ introduce errors in estimating enteric $\mathrm{CH}_{4}$ emissions. The use of a constant value for $Y_{m}$ is a major concern because it can vary considerably with varying DMI and DM digestibility (Appuhamy et al., 2016). It can take values ranging from 3 to $10 \%$ (Mills et al., 2003), and the IPCC $\mathrm{Y}_{\mathrm{m}}$ constants do not encompass this range. Factors such as feed quality, production level (related to DMI), and diet composition affect the proportion of energy lost in the form of $\mathrm{CH}_{4}$ (e.g., Moraes et al., 2014; Jayasundara et al., 2016). Hence, assigning a constant $Y_{m}$ can lead to considerable uncertainty in the emission estimates, particularly in regions with diverse production systems. Several authors have challenged the use of constant $\mathrm{Y}_{\mathrm{m}}$ value of $6.5 \pm 1.0 \%$ of GEI (IPCC, 2006) across different regions of the world for dairy cattle (e.g., Kebreab et al., 2008). For example, the average $Y_{m}$ for dairy cattle has been reported to be 5.4 to $5.7 \%$ for North America (Kebreab et al., 2008; Appuhamy et al., 2016; Jayasundara et al., 2016; Niu et al., 2018). The uncertainty around $\mathrm{Y}_{\mathrm{m}}$ is about 1 percentage point, which is quite large and leads to gross overestimation of enteric $\mathrm{CH}_{4}$ emissions for North America. In Europe, the $\mathrm{Y}_{\mathrm{m}}$ varies between 6.0 and 6.9\% (7.1 for Switzerland; Zeitz et al., 2012; Niu et al., 2018), and in Australia and New Zealand, the value is closer to the most recent IPCC recommendations at $6.6 \%$ (Appuhamy et al., 2016). Hence, recommendations for estimating enteric $\mathrm{CH}_{4}$ emissions from dairy cows should be made on a regional rather than global basis. The analysis of Appuhamy et al. (2016) showed that no single empirical model is superior to others in all regions of the world. Any particular model may have strengths in simulating some aspects of the $\mathrm{CH}_{4}$ emissions but not all at the same time. Multi-model ensemble methodology has become a widely accepted approach to improve prediction by taking advantage of complementary individual models and adjusting various biases, particularly in hydrology, climate, economy, and recently in crop growth models (Huang et al., 2017). If a regional or even global estimate of $Y_{m}$ is desired, it may be possible to use the top 5 to 10 models within a region in a multiple $\mathrm{CH}_{4}$ model ensemble to improve region-wide prediction.

Mechanistic Models. A limited number of mechanistic models have been developed to predict nutrient absorption from the digestive tract, including VFA, and these models have been modified to predict enteric $\mathrm{CH}_{4}$ emissions by adding hydrogen calculations. These include the "Molly" model that describes nutrient utilization in cattle with the ability to predict enteric $\mathrm{CH}_{4}$ emissions through hydrogen balance in the rumen (Baldwin, 1995); the "Cowpoll" model, which is based on a series of dynamic, deterministic, and nonlinear differential equations of nutrient utilization and includes $\mathrm{CH}_{4}$ production in the rumen and hindgut (Dijkstra et al., 1992; Mills et al., 2001; Bannink et al., 2011); 
the Nordic cow model "Karoline," which is a dynamic, mechanistic model describing digestion and metabolism in dairy cows (Danfær et al., 2006; Huhtanen et al., 2015b); and the "AusBeef" model, which is a dynamic, mechanistic, and deterministic model of beef cattle production that uses a detailed representation of biological processes to determine nutrient utilization and $\mathrm{CH}_{4}$ emissions (based on Nagorcka et al., 2000, which is an adapted version of the model of Dijkstra, 1994).

In all extant mechanistic models, the underlying principles in predicting $\mathrm{CH}_{4}$ emissions are similar. The models predict nutrient digestion, absorption, microbial growth, and fermentation stoichiometry to determine type and amount of VFA production, hydrogen, and ultimately enteric $\mathrm{CH}_{4}$ emissions during ruminal (and sometimes hindgut) fermentation. The models differ mainly in the number of microbial groups included, source and particle size of feed, substrates for VFA production, and VFA stoichiometry. Methane emissions are calculated in a similar way in all models, by calculating hydrogen balance in the rumen and assuming that any excess hydrogen is converted to $\mathrm{CH}_{4}$. However, hydrogen production by cattle can be substantial, depending on diet composition, and hydrogen production shows large diurnal variation with peaks of production shortly after a meal (e.g., Hristov et al., 2015b; Guyader et al., 2015; Olijhoek et al., 2016; van Gastelen et al., 2017). Prediction accuracy of $\mathrm{CH}_{4}$ emissions in mechanistic models depends largely on the accuracy of the stoichiometric models used and their accuracy to predict VFA molar proportions (Bannink et al., 2011). Alemu et al. (2011) evaluated several stoichiometric models and reported that their performance varies widely ranging from 5.2 to $43.2 \%$ RMSPE. There is a scarcity of studies that measured VFA production rates, because this requires the use of isotopes to differentiate between VFA concentrations (which are net production) observed in the rumen and production rates.

Researchers in the Netherlands apply a Tier 3 approach for national inventory of dairy cattle $\mathrm{CH}_{4}$ emissions (based on country-specific experimental data and typically involving modeling and higher resolution landuse and land-use change data) using a mechanistic model (Bannink et al., 2011). Using this approach, Bannink et al. (2016) were able to explain part of the observed variation in enteric $\mathrm{CH}_{4}$ emissions due to variation in grass silage quality, and DMI. Several model comparisons have been performed by Benchaar et al. (1998) and Kebreab et al. (2008), showing that the Cowpoll model agreed with observed data better than Molly or other empirical models for $\mathrm{CH}_{4}$ emission from dairy cattle. For feedlot cattle, the Molly model performed better than Cowpoll [before Ellis et al. (2014) improved the prediction of $\mathrm{CH}_{4}$ emissions and representation of rumen fermentation for finishing beef cattle]. Kass et al. (2017) compared the Molly model with Karoline model in their ability to predict $\mathrm{CH}_{4}$ emissions and concluded that, although both models predicted $\mathrm{CH}_{4}$ emissions reasonably well, the Karoline model was more accurate based on smaller mean and slope bias. The limitation

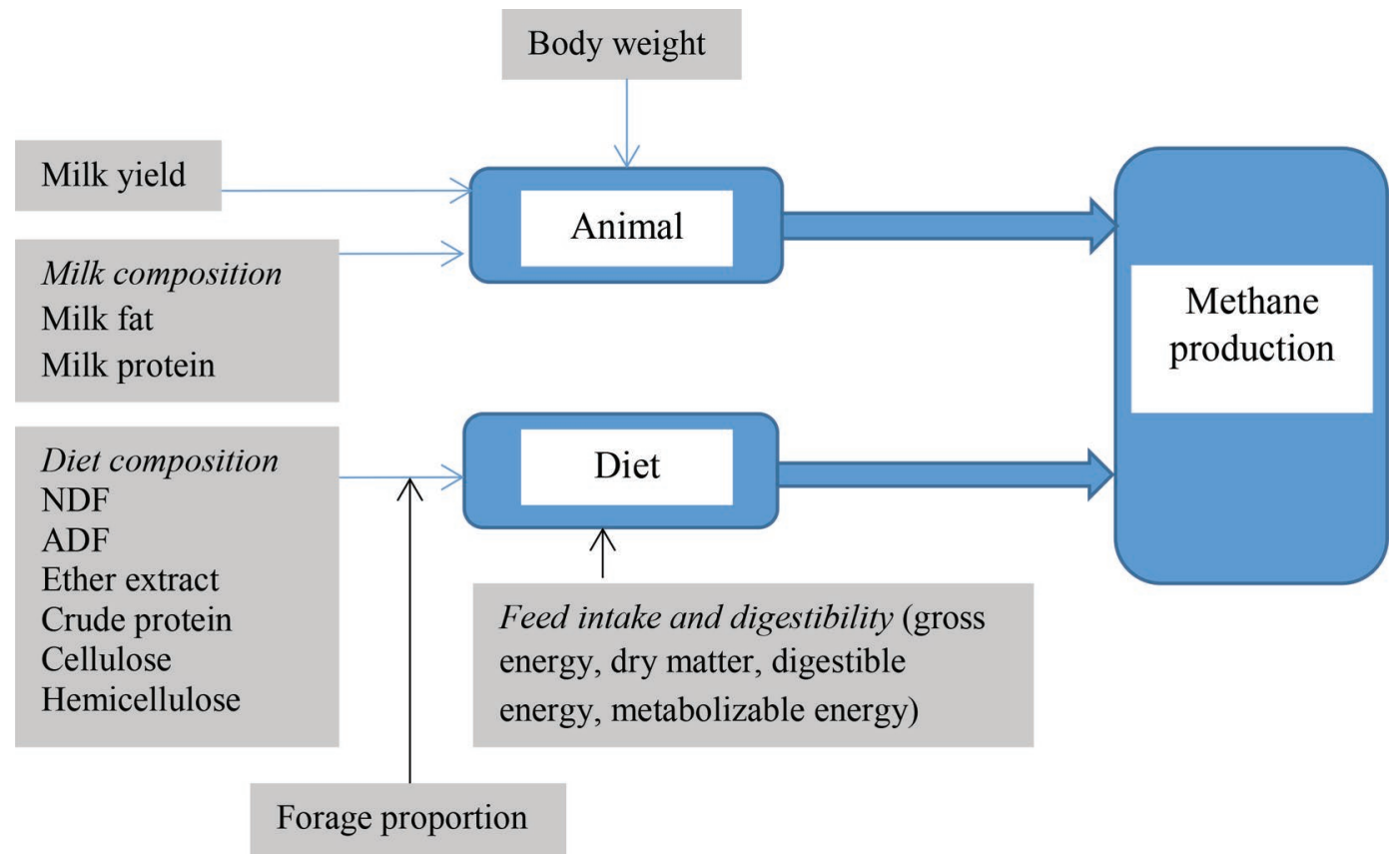

Figure 3. Diet and animal factors used to estimate enteric methane production in extant empirical models. Color version available online. 
to the extensive use of mechanistic models of nutrient utilization is that they require inputs that may not be available at the production system level.

\section{Critical Data Gaps Limiting Enteric $\mathrm{CH}_{4}$ Quantification}

Ellis et al. (2010) evaluated the prediction ability of several models to estimate enteric $\mathrm{CH}_{4}$ emissions observed under various experimental conditions and concluded that, in general, predictions of these broadly applicable models were poor (based on RMSPE). According to Moraes et al. (2014), the poor predictive ability of current models can be due in part to the relatively small data sets used for model parameterization and the modeling techniques. Except for those that were developed by Moraes et al. (2014) for cattle in North America, most prediction models used a few hundred observations to develop relationships between enteric $\mathrm{CH}_{4}$ emissions and dietary or animal factors. Normally, this number would not encompass the diversity of diets and animal factors in various regions of the world. Therefore, empirical models should ideally be developed from a database containing well over 1,000 individual observations or treatment means with accompanying information about dietary and animal factors that are known to affect enteric $\mathrm{CH}_{4}$ emissions. In some cases, the improvement could be limited to the average animal, and observed variation might not be explained if key parameters are not included. Such databases will allow the development of robust estimates of average $\mathrm{CH}_{4}$ emissions that can be tailored to be specific to a region and allow for various types of models ranging from simple one-covariate models to much more complex models that include several dietary and animal variables. Most of the $\mathrm{CH}_{4}$ emission data in the literature originate from Europe, North America, Australia, and New Zealand (Appuhamy et al., 2016). Recently, there has been an increase in data being published from Central and South America (e.g., Dini et al., 2012; Muñoz et al., 2015), but there is still a dearth of data from Asia and Africa. Further research is required to produce data from indigenous and improved breeds of dairy cattle in Asia and Africa, and the data should encompass the production systems and feeds available in those regions. In our opinion, further development of enteric $\mathrm{CH}_{4}$ prediction models would need regional data sets with as many data points as possible that have reliable DMI and $\mathrm{CH}_{4}$ emission measurements. For the purpose of national inventories, the IPCC Tier 2 model with region-specific $Y_{m}$ factors would be most suitable.

Statistical methods that have been used in developing empirical models to date may not be appropriate because of the limitation of the framework used, such as not including random effects of animals or studies. Most of the current models (e.g., Ramin and Huhtanen, 2013) were developed with parametric inference gained from the likelihood function (frequentist statistical method). In this method, only a sequential application of simple significance tests can be calculated. In addition, only nested models can be compared, and different models are selected if alternative procedures or starting covariates are included in the statistical procedures. On the other hand, Bayesian methods are subjective and use prior beliefs to define a prior probability distribution on the possible values of the unknown parameters. Some examples of implementation of Bayesian modeling in animal nutrition and $\mathrm{CH}_{4}$ emission prediction include those by Strathe et al. (2012) and Moraes et al. (2014). Even mechanistic, dynamic ruminant nutrition models used for enteric $\mathrm{CH}_{4}$ emissions prediction can benefit from Bayesian methods to capture the inherent variability of the biological system under study and provide an assessment of the error associated with complex model results (Reed et al., 2016). Model evaluation methods have also advanced and it is possible to run Monte Carlo simulations and cross-validation techniques for large data sets and compare the predictive abilities of multiple $\mathrm{CH}_{4}$ prediction models. Models should be developed at different complexity levels, which require different levels of activity data and dietary information for better functionality, as users will have various levels of information available to them in making predictions. In addition, the trade-off between model complexity and predictive ability should be quantified so users can decide whether the extra resources required for better prediction are justified by the increase in prediction. The trade-off has to be determined in the context of the aim for which the models are going to be used, such as for national inventory, assessment of mitigation options, and others.

Therefore, it is important that future models for a broad application be developed from large data sets with collaboration of scientists worldwide, as in the GLOBAL NETWORK project, and using robust stateof-the-art statistical techniques for model development and evaluation. The data sets should encompass a wide range of diets and production systems within regions and globally. It is also possible to develop a multi-model ensemble to improve enteric $\mathrm{CH}_{4}$ emission prediction and determine uncertainty associated with the prediction.

\section{CONCLUSIONS}

There are large uncertainties in livestock $\mathrm{CH}_{4}$ national and global inventories; sources of uncertainties in enteric $\mathrm{CH}_{4}$ emission include animal inventories, 
feed DMI, ingredient and chemical composition of the diet, and $\mathrm{CH}_{4}$ emission factors. There is also significant uncertainty associated with enteric $\mathrm{CH}_{4}$ measurements. Widely used measurement techniques are respiration chambers, the $\mathrm{SF}_{6}$ tracer technique, and the GreenFeed system. All 3 methods need to be correctly and appropriately used to generate reliable and accurate data and valid tests of effects of diets and other treatments on enteric $\mathrm{CH}_{4}$ emission or animal variation in $\mathrm{CH}_{4}$ emission rates; some uncertainty remains as direct comparisons of techniques have shown inconsistent results. We emphasize that each of these techniques can have low accuracy and precision or produce misleading results if not properly implemented. Detailed guidelines for these techniques have been published and should be followed rigorously by researchers. Enteric $\mathrm{CH}_{4}$ prediction models are based on various animal or feed characteristic inputs but are dominated by DMI in one form or another. Therefore, accurate prediction of DMI is of pivotal importance for accurate prediction of livestock $\mathrm{CH}_{4}$ emissions. It is recommended that simplified enteric $\mathrm{CH}_{4}$ prediction models based on DMI alone or DMI and limited feed- or animal-related inputs be developed and used for inventory purposes, where sufficient details or accuracy on dietary inputs are lacking. Broadly applicable and robust prediction models must be developed from large data sets generated through collaboration of scientists worldwide. To achieve high prediction accuracy, these data sets should encompass a wide range of diets and production systems within regions and globally. The uncertainty in enteric $\mathrm{CH}_{4}$ prediction can be reduced by developing region-specific $Y_{m}$ values. Similarly, the uncertainty in DMI estimation can be decreased by using DMI prediction equations that are region-specific instead of the GEI approach of IPCC Tier 2.

\section{ACKNOWLEDGMENTS}

The authors acknowledge funding for the GLOBAL NETWORK project by The Joint Programming Initiative on Agriculture, Food Security and Climate Change (FACCE-JPI; https://www.faccejpi.com/) and project contributors funding sources (for details, see Acknowledgments in Niu et al., 2018).

\section{REFERENCES}

Alemu, A. W., J. Dijkstra, A. Bannink, J. France, and E. Kebreab. 2011. Rumen stoichiometric models and their contribution and challenges in predicting enteric methane production. Anim. Feed Sci. Technol. 166-167:761-778.

Alemu, A. W., D. Vyas, G. Manafiazar, J. A. Basarab, and K. A. Beauchemin. 2017. Enteric methane emissions from low- and high- residual feed intake beef heifers measured using GreenFeed and respiration chamber techniques. J. Anim. Sci. 95:3727-3737.

Appuhamy, J. A. D. R. N., J. France, and E. Kebreab. 2016. Models for predicting enteric methane emissions from dairy cows in North America, Europe, and Australia and New Zealand. Glob. Chang. Biol. 22:3039-3056.

Appuhamy, J. A. D. R. N., L. E. Moraes, C. Wagner-Riddle, D. P. Casper, and E. Kebreab. 2018. Predicting manure volatile solid output of lactating dairy cows. J. Dairy Sci. 101:820-829. https:// doi.org/10.3168/jds.2017-12813.

Arbre, M., Y. Rochette, J. Guyader, C. Lascoux, L. M. Gómez, M. Eugène, D. P. Morgavi, G. Renand, M. Doreau, and C. Martin. 2016. Repeatability of enteric methane determinations from cattle using either the $\mathrm{SF}_{6}$ tracer technique or the GreenFeed system. Anim. Prod. Sci. 56:238-243.

Arnerdal, S. 2005. Predictions for voluntary dry matter intake in dairy cows. Thesis. Department of Animal Nutrition and Management, Swedish University of Agricultural Sciences, Uppsala, Sweden.

Arthur, P. F., I. M. Barchia, C. Weber, T. Bird-Gardiner, K. A. Donoghue, R. M. Herd, and R. S. Hegarty. 2017. Optimizing test procedures for estimating daily methane and carbon dioxide emissions in cattle using short-term breath measures. J. Anim. Sci. 95:645-656. https://doi.org/10.2527/jas.2016.0700.

Baldwin, R. L. 1995. Modeling Ruminant Digestion and Metabolism. Chapman \& Hall, London, UK.

Bannink, A., M. W. van Schijndel, and J. Dijkstra. 2011. A model of enteric fermentation in dairy cows to estimate methane emission for the Dutch National Inventory Report using the IPCC Tier 3 approach. Anim. Feed Sci. Technol. 166-67:603-618.

Bannink, A., D. Warner, B. Hatew, J. L. Ellis, and J. Dijkstra. 2016. Quantifying effects of grassland management on enteric methane emission. Anim. Prod. Sci. 56:409-416.

Benchaar, C., J. Rivest, C. Pomar, and J. Chiquette. 1998. Prediction of methane production from dairy cows using existing mechanistic models and regression equations. J. Anim. Sci. 76:617-627.

Berends, H., W. J. J. Gerrits, J. France, J. L. Ellis, S. M. van Zijderveld, and J. Dijkstra. 2014. Evaluation of the $\mathrm{SF}_{6}$ tracer technique for estimating methane emission rates with reference to dairy cows using a mechanistic model. J. Theor. Biol. 353:1-8.

Berndt, A., T. M. Boland, M. H. Deighton, J. I. Gere, C. Grainger, R. S. Hegarty, A. D. Iwaasa, J. P. Koolaard, K. R. Lassey, D. Luo, R. J. Martin, C. Martin, P. J. Moate, G. Molano, C. S. PinaresPatiño, B. E. Ribaux, N. M. Swainson, G. W. Waghorn, and S. R. O. Williams. 2014. Guidelines for use of sulphur hexafluoride $\left(\mathrm{SF}_{6}\right)$ tracer technique to measure enteric methane emissions from ruminants. M. G. Lambert, ed. New Zealand Agricultural Greenhouse Gas Research Centre. Ministry for Primary Industries, Wellington, New Zealand.

Bird-Gardiner, T., P. F. Arthur, I. M. Barchia, K. A. Donoghue, and R. M. Herd. 2017. Phenotypic relationships among methane production traits assessed under ad libitum feeding of beef cattle. J. Anim. Sci. 95:4391-4398.

Blaxter, K. L., and J. L. Clapperton. 1965. Prediction of the amount of methane produced by ruminants. Br. J. Nutr. 19:511-522. https:// doi.org/10.1079/BJN19650046.

Branco, A. F., F. Giallongo, T. Frederick, H. Weeks, J. Oh, and A. N. Hristov. 2015. Effect of technical cashew nut shell liquid on rumen methane production and lactation performance of dairy cows. J. Dairy Sci. 98:4030-4040.

Brask, M., M. R. Weisbjerg, A. L. F. Hellwing, A. Bannink, and P. Lund. 2015. Methane production and diurnal variation measured in dairy cows and predicted from fermentation pattern and nutrient or carbon flow. Animal 9:1795-1806. https://doi.org/10.1017/ S1751731115001184.

State of California. 2017. California Legislative Information: SB-1383 Short-lived climate pollutants: methane emissions: dairy and livestock: organic waste: landfills. Accessed Jun. 30, 2017. https:// leginfo.legislature.ca.gov/faces/billNavClient.xhtml?bill_id= 201520160 SB1383.

Chagunda, M. G. G., D. Ross, J. Rooke, T. Yan, J. L. Douglas, L. Poret, N. R. McEwan, P. Teeranavattanakul, and D. J. Roberts. 
2013. Measurement of enteric methane from ruminants using a hand-held laser methane detector. Acta Agric. Scand. A Anim. Sci. 63:68-75.

Charmley, E., S. R. O. Williams, P. J. Moate, R. S. Hegarty, R. M. Herd, V. H. Oddy, P. Reyenga, K. M. Staunton, A. Anderson, and M. C. Hannah. 2016. A universal equation to predict methane production of forage-fed cattle in Australia. Anim. Prod. Sci. $56: 169-180$.

Danfær, A., P. Huhtanen, P. Udén, J. Sveinbjörnsson, and H. Volden. 2006. The Nordic dairy cow model, Karoline-Description. Pages 383-406 in Nutrient Digestion and Utilization in Farm Animals: Modelling Approaches. E. Kebreab, J. Dijkstra, A. Bannink, W. J. J. Gerrits, and J. France, ed. CABI Publishing, Wallingford, UK.

Deighton, M. H., S. R. O. Williams, M. C. Hannah, R. J. Eckard, T. M. Boland, W. J. Wales, and P. J. Moate. 2014. A modified sulphur hexafluoride tracer technique enables accurate determination of enteric methane emissions from ruminants. Anim. Feed Sci. Technol. 197:47-63.

Dijkstra, J. 1994. Simulation of the dynamics of protozoa in the rumen. Br. J. Nutr. 72:679-699.

Dijkstra, J., H. D. St. C. Neal, D. E. Beever, and J. France. 1992. Simulation of nutrient digestion, absorption, and outflow in the rumen: Model description. J. Nutr. 122:2239-2256.

Dini, Y., J. Gere, C. Briano, M. Manetti, P. Juliarena, V. Picasso, R. Gratton, and L. Astigarraga. 2012. Methane emission and milk production of dairy cows grazing pastures rich in legumes or rich in grasses in Uruguay. Animals (Basel) 2:288-300.

Dittmann, M. T., K. J. Hammond, P. Kirton, D. J. Humphries, L. A. Crompton, S. Ortmann, T. H. Misselbrook, K.-H. Südekum, A. Schwarm, M. Kreuzer, C. K. Reynolds, and M. Clauss. 2016. Influence of ruminal methane on digesta retention and digestive physiology in non-lactating dairy cattle. Br. J. Nutr. 116:763-773.

Doreau, M., A. Arbre, Y. Rochette, C. Lascoux, M. Eugène, and C. Martin. 2018. Comparison of 3 methods for estimating enteric methane and carbon dioxide emission in nonlactating cows. J. Anim. Sci. https://doi.org/10.1093/jas/sky033.

Dorich, C. D., R. K. Varner, A. B. D. Pereira, R. Martineau, K. J. Soder, and A. F. Brito. 2015. Short communication: use of a portable automated open-circuit gas quantification system and the sulfur hexafluoride tracer technique for measuring enteric methane emissions in Holstein cows fed ad libitum or restricted. J. Dairy Sci. 98:2676-2681.

EDGAR. 2011. Emission Database for Global Atmospheric Research (EDGAR), release version 4.2. European Commission, Brussels, Belgium.

Eiler, J. M. 2007. "Clumped-isotope" geochemistry: The study of naturally-occurring, multiply-substituted isotopologues. Earth Planet. Sci. Lett. 262:309-327. https://doi.org/10.1016/j.epsl.2007.08.020.

Ellis, J. L., A. Bannink, J. France, E. Kebreab, and J. Dijkstra. 2010. Prediction of enteric methane production by dairy cows in whole farm models. Glob. Change Biol. 16:3246-3256.

Ellis, J. L., J. Dijkstra, A. Bannink, E. Kebreab, S. Archibeque, C. Benchaar, K. A. Beauchemin, J. D. Nkrumah, and J. France. 2014. Improving the prediction of methane production and representation of rumen fermentation for finishing beef cattle within a mechanistic model. Can. J. Anim. Sci. 94:509-524.

FAOSTAT. 2017. Statistical database. Food and Agriculture Organization of the United Nations (FAO), Rome, Italy. Updated December 22, 2016; accessed July 1, 2017. http://www.fao.org/faostat/ en/\#data.

Flatt, W. P., P. J. Van Soest, J. F. Sykes, and L. A. Moore. 1958. A description of the Energy Metabolism Laboratory at the U.S. Department of Agriculture, Agricultural Research Centre in Beltsville, Maryland. Pages 53-64 in Energy Metabolism of Farm Animals. G. Thorbeck, and H. Aersoe, ed. EAAP Publ. No. 8. Statens Husdyrugsudvalg, Copenhagen, Denmark.

Fox, D. G., C. J. Sniffen, J. D. O'Connor, J. B. Russell, and P. J. van Soest. 1992. A net carbohydrate and protein system for evaluating cattle diets: III. Cattle requirements and diet adequacy. J. Anim. Sci. 70:3578-3596.
Gardiner, T. D., M. D. Coleman, F. Innocenti, J. Tompkins, A. Connor, P. C. Garnsworthy, J. M. Moorby, C. K. Reynolds, A. Waterhouse, and D. Wills. 2015. Determination of the absolute accuracy of UK chamber facilities used in measuring methane emissions from livestock. Measurement 66:272-279.

Garnsworthy, P. C., J. Craigon, J. H. Hernandez-Medrano, and N. Saunders. 2012. On-farm methane measurements during milking correlate with total methane production by individual dairy cows. J. Dairy Sci. 95:3166-3180.

Gerrits, W., E. Labussière, J. Dijkstra, C. Reynolds, C. Metges, B. Kuhla, P. Lund, and M. R. Weisbjerg. 2018. Letter to the Editors: Recovery test results as a prerequisite for publication of gaseous exchange measurements. Animal 12:4. https://doi.org/10.1017/ S1751731117002397.

Grainger, C., T. Clarke, S. M. McGinn, M. J. Auldist, K. A. Beauchemin, M. C. Hannah, G. C. Waghorn, H. Clark, and R. J. Eckard. 2007. Methane emissions from dairy cows measured using the sulfur hexafluoride $\left(\mathrm{SF}_{6}\right)$ tracer and chamber techniques. J. Dairy Sci. 90:2755-2766.

Guyader, J., M. Eugène, B. Meunier, M. Doreau, D. P. Morgavi, M. Silberberg, Y. Rochette, C. Gérard, C. Loncke, and C. Martin. 2015. Additive methane-mitigating effect between linseed oil and nitrate fed to cattle. J. Anim. Sci. 93:3564-3577.

Hammond, K. J., L. A. Crompton, A. Bannink, J. Dijkstra, D. R. Yanez-Ruiz, P. O’Kiely, E. Kebreab, M. A. Eugene, Z. Yu, K. J. Shingfield, A. Schwarm, A. N. Hristov, and C. K. Reynolds. 2016a. Review of current in vivo measurement techniques for quantifying enteric methane emission from ruminants. Anim. Feed Sci. Technol. 219:13-30.

Hammond, K. J., D. J. Humphries, L. A. Crompton, C. Green, and C. K. Reynolds. 2015. Methane emissions from cattle: Estimates from short-term measurements using a GreenFeed system compared with measurements obtained using respiration chambers or sulphur hexafluoride tracer. Anim. Feed Sci. Technol. 203:41-52.

Hammond, K. J., A. K. Jones, D. J. Humphries, L. A. Crompton, and C. K. Reynolds. 2016b. Effects of diet forage source and neutraldetergent fiber content on milk production of dairy cattle and methane emission determined using GreenFeed and respiration chamber techniques. J. Dairy Sci. 99:7904-7917.

Haque, M. N., H. H. Hansen, I. M. L. D. Storm, and J. Madsen. 2017. Comparative methane estimation from cattle based on total $\mathrm{CO}_{2}$ production using different techniques. Anim. Nutr. 3:175-179.

Hristov, A. N., M. Harper, R. Meinen, R. Day, J. Lopes, T. Ott, A. Venkatesh, and C. A. Randles. 2017. Discrepancies and uncertainties in bottom-up gridded inventories of livestock methane emissions for the contiguous United States. Environ. Sci. Technol. 51:13668-13677. https://doi.org/10.1021/acs.est.7b03332.

Hristov, A. N., K. A. Johnson, and E. Kebreab. 2014. Livestock methane emissions in the United States. Proc. Natl. Acad. Sci. USA 111:E1320. https://doi.org/10.1073/pnas.1401046111.

Hristov, A. N., J. Oh, J. Firkins, J. Dijkstra, E. Kebreab, G. Waghorn, H. P. S. Makkar, A. T. Adesogan, W. Yang, C. Lee, P. J. Gerber, B. Henderson, and J. M. Tricarico. 2013. Mitigation of methane and nitrous oxide emissions from animal operations: I. A review of enteric methane mitigation options. J. Anim. Sci. 91:5045-5069.

Hristov, A. N., J. Oh, F. Giallongo, T. Frederick, M. Harper, H. Weeks, A. Branco, P. Moate, M. Deighton, R. Williams, M. Kindermann, and S. Duval. 2015b. An inhibitor persistently decreased enteric methane emission from dairy cows with no negative effect on milk production. Proc. Natl. Acad. Sci. USA 112:10663-10668. https:// doi.org/10.1073/pnas.1504124112.

Hristov, A. N., J. Oh, F. Giallongo, T. Frederick, M. T. Harper, H. Weeks, A. F. Branco, W. J. Price, P. J. Moate, M. H. Deighton, S. R. O. Williams, M. Kindermann, and S. Duval. 2016. Short communication: Comparison between the GreenFeed system and the sulfur hexafluoride tracer technique for measuring enteric methane emissions from dairy cows. J. Dairy Sci. 99:5461-5465.

Hristov, A. N., J. Oh, F. Giallongo, T. Frederick, H. Weeks, P. R. Zimmerman, R. A. Hristova, S. R. Zimmerman, and A. F. Branco. 2015a. The use of an automated system (GreenFeed) to moni- 
tor enteric methane and carbon dioxide emissions from ruminant animals. J. Vis. Exp. 103:e52904. https://doi.org/10.3791/52904.

Hristov, A. N., W. J. Price, and B. Shafii. 2004. A meta-analysis examining the relationship among dietary factors, dry matter intake, and milk yield and milk protein yield in dairy cows. J. Dairy Sci. $87: 2184-2196$.

Huang, X., G. Huang, C. Yu, S. Ni, and L. Yu. 2017. A multiple crop model ensemble for improving broad-scale yield prediction using Bayesian model averaging. Field Crops Res. 211:114-124.

Huhtanen, P., E. H. Cabezas-Garcia, S. Utsumi, and S. Zimmerman. 2015a. Comparison of methods to determine methane emissions from dairy cows in farm conditions. J. Dairy Sci. 98:3394-3409.

Huhtanen, P., M. Ramin, and A. N. Hristov. 2018. Comparison of methane production measured by the GreenFeed system and predicted by empirical equations. J. Dairy Sci. https://doi.org/10 .3168/jds.2017-14218.

Huhtanen, P., M. Ramin, and P. Udén. 2015b. Nordic dairy cow model Karoline in predicting methane emissions: 1. Model description and sensitivity analysis. Livest. Sci. 178:81-93.

Ingvartsen, K. L. 1994. Models of voluntary food intake in cattle. Livest. Prod. Sci. 39:19-38.

IPCC. 1997. Revised 1996 IPCC Guidelines for National Greenhouse Gas Inventories. Intergovernmental Panel on Climate Change (IPCC)/Organisation for Economic Co-operation and Development (OECD)/International Energy Agency (IEA), Bracknell, UK.

IPCC. 2006. 2006 IPCC Guidelines for National Greenhouse Gas Inventories. Intergovernmental Panel on Climate Change, Institute for Global Environmental Strategies, Kanagawa, Japan.

IPCC. 2014. Working Group III-Mitigation of climate change. Chapter 11: Agriculture, forestry and other land use (AFOLU). Cambridge Univ. Press, Cambridge, UK.

Jayasundara, S., J. A. D. R. N. Appuhamy, E. Kebreab, and C. Wagner-Riddle. 2016. Methane and nitrous oxide emissions from Canadian dairy farms and mitigation options: An updated review. Can. J. Anim. Sci. 96:306-331.

Jensen, L. M., N. I. Nielsen, E. Nadeau, B. Markussen, and P. Nørgaard. 2015. Evaluation of five models predicting feed intake by dairy cows fed total mixed rations. Livest. Sci. 176:91-103.

Johnson, K, H. Huyler, H. Westberg, B. Lamb, and P. Zimmerman. 1994. Measurement of methane emissions from ruminant livestock using a sulfur hexafluoride tracer technique. Environ. Sci. Technol. 28:359-362.

Jonker, A., G. Molano, C. Antwi, and G. C. Waghorn. 2016. Enteric methane and carbon dioxide emissions measured using respiration chambers, the sulfur hexafluoride tracer technique, and a GreenFeed head-chamber system from beef heifers fed alfalfa silage at three allowances and four feeding frequencies. J. Anim. Sci. 94:4326-4337.

Kass, M., M. D. Hanigan, M. Ramin, and P. Huhtanen. 2017. Comparison of Molly and Karoline models to predict methane emissions in cattle. J. Dairy Sci. 100(Suppl. 2):327. (Abstr.)

Kebreab, E., K. Clarke, C. Wagner-Riddle, and J. France. 2006. Methane and nitrous oxide emissions from Canadian animal agriculture - A review. Can. J. Anim. Sci. 86:135-158.

Kebreab, E., K. A. Johnson, S. L. Archibeque, D. Pape, and T. Wirth. 2008. Model for estimating enteric methane emissions from US cattle. J. Anim. Sci. 86:2738-2748.

Kirschke, S., P. Bousquet, P. Ciais, M. Saunois, J. G. Canadell, E. J. Dlugokencky, P. Bergamaschi, D. Bergmann, D. R. Blake, L. Bruhwiler, P. Cameron-Smith, S. Castaldi, F. Chevallier, L. Feng, A. Fraser, M. Heimann, E. L. Hodson, S. Houweling, B. Josse, P. J. Fraser, P. B. Krummel, J.-F. Lamarque, R. L. Langenfelds, C. Le Quéré, V. Naik, S. O'Doherty, P. I. Palmer, I. Pison, D. Plummer, B. Poulter, R. G. Prinn, M. Rigby, B. Ringeval, M. Santini, M. Schmidt, D. T. Shindell, I. J. Simpson, R. Spahni, L. P. Steele, S. A. Strode, K. Sudo, S. Szopa, G. R. van der Werf, A. Voulgarakis, M. van Weele, R. F. Weiss, J. E. Williams, and G. Zeng. 2013. Three decades of global methane sources and sinks. Nat. Geosci. 6:813-823.
Klevenhusen, F., S. M. Bernasconi, M. Kreuzer, and C. R. Soliva. 2010. Experimental validation of the Intergovernmental Panel on Climate Change default values for ruminant-derived methane and its carbon-isotope signature. Anim. Prod. Sci. 50:159-167.

Knapp, J. R., G. L. Laur, P. A. Vadas, W. P. Weiss, and J. M. Tricarico. 2014. Enteric methane in dairy cattle production: Quantifying the opportunities and impact of reducing emissions. J. Dairy Sci. 97:3231-3261. https://doi.org/10.3168/jds.2013-7234.

Kriss, M. 1931. A comparison of feeding standards for dairy cows, with special reference to energy requirements. J. Nutr. 4:141-161.

Krizsan, S. J., A. Sairanen, A. Höjer, and P. Huhtanen. 2014. Evaluation of different feed intake models for dairy cows. J. Dairy Sci. 97:2387-2397.

Leiva, E., M. B. Hall, and H. H. van Horn. 2000. Performance of dairy cattle fed citrus pulp or corn products as sources of neutral detergent-soluble carbohydrates. J. Dairy Sci. 83:2866-2875.

Luo, L. J. 2010. Breeding for water-saving and drought-resistance rice (WDR) in China. J. Exp. Bot. 61:3509-3517.

Maasakkers, J. D., D. J. Jacob, M. P. Sulprizio, A. J. Turner, M. Weitz, T. Wirth, C. Hight, M. DeFigueiredo, M. Desai, R. Schmeltz, L. L. Hockstad, A. A. Bloom, K. W. Bowman, S. Jeong, and M. L. Fischer. 2016. Gridded national inventory of U.S. methane emissions. Environ. Sci. Technol. 50:13123-13133.

Madsen, J., B. S. Bjerg, T. Hvelplund, M. R. Weisbjerg, and P. Lund. 2010. Methane and carbon dioxide ratio in excreted air for quantification of the methane production from ruminants. Livest. Sci. 129:223-227.

Mertens, D. R. 1995. Methods in modelling feeding behavior and intake in herbivores. Pages 1-17 in IVth Int. Symp. Nutr. Herbivores. Inst. Natl. Agron., Paris-Grignon, and INRA, Paris, France.

Miller, S. M., S. C. Wofsy, A. M. Michalak, E. A. Kort, A. E. Andrews, S. C. Biraud, E. J. Dlugokencky, J. Eluszkiewicz, M. L. Fischer, G. Janssens-Maenhout, B. R. Miller, J. B. Miller, S. A. Montzka, T. Nehrkorn, and C. Sweeney. 2013. Anthropogenic emissions of methane in the United States. Proc. Natl. Acad. Sci. USA 110:20018-20022.

Mills, J. A. N., J. Dijkstra, A. Bannink, S. B. Cammell, E. Kebreab, and J. France. 2001. A mechanistic model of whole-tract digestion and methanogenesis in the lactating dairy cow: Model development, evaluation, and application. J. Anim. Sci. 79:1584-1597.

Mills, J. A. N., E. Kebreab, C. Yates, L. A. Crompton, S. B. Cammell, M. S. Dhanoa, R. E. Agnew, and J. France. 2003. Alternative approaches to predicting methane emissions from dairy cows. J. Anim. Sci. 81:3141-3150.

Moate, P. J., M. Deighton, and S. R. O. Williams. 2012. Intake effects on methane emissions from dairy cows. Pages 11-12 in Proc. Climate Change Research Strategy For Primary Industries Conference, Melbourne, Australia. Department of Agriculture, Fisheries and Forestry, Australia.

Moraes, L. E., A. B. Strathe, J. G. Fadel, D. P. Casper, and E. Kebreab. 2014. Prediction of enteric methane emissions from cattle. Glob. Chang. Biol. 20:2140-2148.

Muñoz, C., S. Hube, J. M. Morales, T. Yan, and E. M. Ungerfeld. 2015. Effects of concentrate supplementation on enteric methane emissions and milk production of grazing dairy cows. Livest. Sci. 175:37-46.

Muñoz, C., T. Yan, D. A. Wills, S. Murray, and A. W. Gordon. 2012. Comparison of the sulphur hexafluoride tracer and respiration chamber techniques for estimating methane emissions and correction for rectum methane output from dairy cows. J. Dairy Sci. 95:3139-3148.

Murray, R. M., A. M. Bryant, and R. A. Leng. 1976. Rates of production of methane in the rumen and large intestine of sheep. Br. J. Nutr. 36:1-14.

Myhre, G., D. Shindell, F.-M. Bréon, W. Collins, J. Fuglestvedt, J Huang, D. Koch, J.-F. Lamarque, D. Lee, B. Mendoza, T. Nakajima, A. Robock, G. Stephens, T. Takemura, and H. Zhang. 2013. Anthropogenic and Natural Radiative Forcing. Pages 659-740 in Climate Change 2013: The Physical Science Basis. Contribution of Working Group I to the Fifth Assessment Report of the Intergov- 
ernmental Panel on Climate Change. T. F. Stocker, D. Qin, G.-K. Plattner, M. Tignor, S. K. Allen, J. Boschung, A. Nauels, Y. Xia, V. Bex, and P. M., Midgley, ed. Cambridge University Press, New York, NY.

Nagorcka, B. N., G. L. R. Gordon, and R. A. Dynes. 2000. Towards a more accurate representation of fermentation in mathematical models in the rumen. Pages 37-48 in Modelling Nutrient Utilization in Farm Animals. J. P. McNamara, J. France, and D. Beever, ed. CAB International, New York, NY.

NASS. 2017. National Agricultural Statistics Service, Quick Stats 2.0. Accessed Jun. 17, 2017. https://www.nass.usda.gov/Quick_Stats/.

Negussie, E., Y. de Haas, F. Dehareng, R. Dewhurst, J. Dijkstra, N. Gengler, D. P. Morgavi, H. Soyeurt, S. van Gastelen, T. Yan, and F. Biscarini. 2017. Invited review: Large-scale indirect measurements for enteric methane emissions in dairy cattle: A review of proxies and their potential for use in management and breeding decisions. J. Dairy Sci. 100:2433-2453.

Nisbet, E. G., E. J. Dlugokencky, M. R. Manning, D. Lowry, R. E. Fisher, J. L. France, S. E. Michel, J. B. Miller, J. W. C. White, B. Vaughn, P. Bousquet, J. A. Pyle, N. J. Warwick, M. Cain, R. Brownlow, G. Zazzeri, M. Lanoisellé, A. C. Manning, E. Gloor, D. E. J. Worthy, E.-G. Brunke, C. Labuschagne, E. W. Wolff, and A. L. Ganesan. 2016. Rising atmospheric methane: 2007-2014 growth and isotopic shift. Global Biogeochem. Cycles 30:1356-1370.

Niu, M., E. Kebreab, A. N. Hristov, J. Oh, C. Arndt, A. Bannink, A. R. Bayat, A. F. Brito, T. Boland, D. Casper, L. A. Crompton, J. Dijkstra, M. A. Eugène, P. C. Garnsworthy, M. N. Haque, A. L. F. Hellwing, P. Huhtanen, M. Kreuzer, B. Kuhla, P. Lund, J. Madsen, C. Martin, S. C. McClelland, M. McGee, P. J. Moate, S. Muetzel, C. Muñoz, P. O'Kiely, N. Peiren, C. K. Reynolds, A. Schwarm, K. J. Shingfield, T. M. Storlien, M. R. Weisbjerg, D. R. Yáñez-Ruiz, and Z. Yu. 2018. Prediction of enteric methane production, yield and intensity in dairy cattle using an intercontinental database. Glob. Chang. Biol. https://doi.org/10.1111/gcb.14094.

NRC. 2000. Nutrient Requirements of Beef Cattle. 7th rev. ed. National Academies Press, Washington, DC.

NRC. 2001. Nutrient Requirements of Dairy Cattle. 7th rev. ed. National Academies Press, Washington, DC.

NRC. 2016. Nutrient Requirements of Beef Cattle. 8th, rev. ed. National Academies Press, Washington, DC.

Olijhoek, D. W., A. L. F. Hellwing, M. Brask, M. R. Weisbjerg, O. Højberg, M. K. Larsen, J. Dijkstra, E. J. Erlandsen, and P. Lund. 2016. Effect of dietary nitrate level on enteric methane production, hydrogen emission, rumen fermentation, and nutrient digestibility in dairy cows. J. Dairy Sci. 99:6191-6205.

Pinares-Patiño, C. S., and H. Clark. 2008. Reliability of the sulphur hexafluoride tracer technique for methane emission measurement from individual animals: An overview. Aust. J. Exp. Agric. 48:223229.

Pinares-Patiño, C. S., K. R. Lassey, R. J. Martin, G. Molano, M. Fernandez, S. MacLean, E. Sandoval, D. Luo, and H. Clark. 2011. Assessment of the sulphur hexafluoride $\left(\mathrm{SF}_{6}\right)$ tracer technique using respiration chambers for estimation of methane emissions from sheep. Anim. Feed Sci. Technol. 166-167:201-209.

Ramin, M., and P. Huhtanen. 2013. Development of equations for predicting methane emissions from ruminants. J. Dairy Sci. 96:24762493.

Reed, K. F., G. B. Arhonditsis, J. France, and E. Kebreab. 2016. Technical Note: Bayesian calibration of dynamic ruminant nutrition models. J. Dairy Sci. 99:6362-6370.

Renand, G., and D. Maupetit. 2016. Assessing individual differences in enteric methane emission among beef heifers using the GreenFeed Emission Monitoring system: Effect of the length of testing period on precision. Anim. Prod. Sci. 56:218-223.

Reynolds, C. K., and H. F. Tyrrell. 2000. Energy metabolism in lactating beef heifers. J. Anim. Sci. 78:2696-2705.

Ricci, P., M. G. G. Chagunda, J. Rooke, J. G. Houdijk, C.-A. Duthie, J. Hyslop, R. Roehe, and A. Waterhouse. 2014. Evaluation of the laser methane detector to estimate methane emissions from ewes and steers. J. Anim. Sci. 92:5239-5250.
Rigby, M., S. A. Montzka, R. G. Prinn, J. W. C. White, D. Young, S. O'Doherty, M. F. Lunt, A. L. Ganesan, A. J. Manning, P. G. Simmonds, P. K. Salameh, C. M. Harth, J. Mühle, R. F. Weiss, P. J. Fraser, L. P. Steele, P. B. Krummel, A. McCulloch, and S. Park. 2017. Role of atmospheric oxidation in recent methane growth. Proc. Natl. Acad. Sci. USA 114:5373-5377. https://doi .org/10.1073/pnas.1616426114.

Rischewski, J., A. Bielak, G. Nürnberg, M. Derno, and B. Kuhla. 2017. Rapid Communication: Ranking dairy cows for methane emissions measured using respiration chamber or GreenFeed techniques during early, peak, and late lactation. J. Anim. Sci. 95:3154-3159.

Saunois, M., P. Bousquet, B. Poulter, A. Peregon, P. Ciais, J. G. Canadell, E. J. Dlugokencky, G. Etiope, D. Bastviken, S. Houweling, G. Janssens-Maenhout, F. N. Tubiello, S. Castaldi, R. B. Jackson, M. Alexe, V. K. Arora, D. J. Beerling, P. Bergamaschi, D. R. Blake, G. Brailsford, V. Brovkin, L. Bruhwiler, C. Crevoisier, P. Crill, K. Covey, C. Curry, C. Frankenberg, N. Gedney, L. Höglund-Isaksson, M. Ishizawa, A. Ito, F. Joos, H.-S. Kim, T. Kleinen, P. Krummel, J.-F. Lamarque, R. Langenfelds, R. Locatelli, T. Machida, S. Maksyutov, K. C. McDonald, J. Marshall, J. R. Melton, I. Morino, V. Naik, S. O'Doherty, F.-J. W. Parmentier, P. K. Patra, C. Peng, S. Peng, G. P. Peters, I. Pison, C. Prigent, R. Prinn, M. Ramonet, W. J. Riley, M. Saito, M. Santini, R. Schroeder, I. J. Simpson, R. Spahni, P. Steele, A. Takizawa, B. F. Thornton, H. Tian, Y. Tohjima, N. Viovy, A. Voulgarakis, M. van Weele, G. R. van der Werf, R. Weiss, C. Wiedinmyer, D. J. Wilton, A. Wiltshire, D. Worthy, D. Wunch, X. Xu, Y. Yoshida, B. Zhang, Z. Zhang, and Q. Zhu. 2016. The global methane budget: 2000-2012. Earth Syst. Sci. Data 8:697-751. https://doi.org/10.5194/essd-2016-25.

Schaefer, H., S. E. Mikaloff Fletcher, C. Veidt, K. R. Lassey, G. W. Brailsford, T. M. Bromley, E. J. Dlugokencky, S. E. Michel, J. B. Miller, I. Levin, D. C. Lowe, R. J. Martin, B. H. Vaughn, and J. W. C. White. 2016. A 21st century shift from fossil-fuel to biogenic methane emissions indicated by ${ }^{13} \mathrm{CH}_{4}$. Science $352: 80-84$. https:// doi.org/10.1126/science.aad2705.

Schwietzke, S., O. Sherwood, L. Bruhwiler, J. Miller, G. Etiope, E. Dlugokencky, S. Englund, M. V. Arling, B. Vaughn, J. White, and P. P. Tans. 2016. Upward revision of global fossil fuel methane emissions based on isotopic database. Nature 538:88-91. https:// doi.org/10.1038/nature19797.

Shah, M. A., and M. R. Murphy. 2006. Development and evaluation of models to predict the feed intake of dairy cows in early lactation. J. Dairy Sci. 89:294-306.

Sorg, D., S. Mühlbach, F. Rosner, B. Kuhla, M. Derno, S. Meese, A. Schwarm, M. Kreuzer, and H. Swalve. 2017. The agreement between two next-generation laser methane detectors and respiration chamber facilities in recording methane concentrations in the spent air produced by dairy cows. Comput. Electron. Agric. 143:262-272.

Stolper, D. A., A. M. Martini, M. Clog, P. M. Douglas, S. S. Shusta, D. L. Valentine, A. L. Sessions, and J. M. Eiler. 2015. Distinguishing and understanding thermogenic and biogenic sources of methane using multiply substituted isotopologues. Geo. Cosmo. Acta 161:219-247. https://doi.org/10.1016/j.gca.2015.04.015.

Strathe, A. B., H. Jørgensen, E. Kebreab, and A. Danfær. 2012. Bayesian simultaneous equation models for the analysis of energy intake and partitioning in growing pigs. J. Agric. Sci. 150:764-774.

Sun, H., S. Zhou, Z. Fu, G. Chen, G. Zou, and X. Song. 2016. A two-year field measurement of methane and nitrous oxide fluxes from rice paddies under contrasting climate conditions. Sci. Rep. 6:28255. https://doi.org/10.1038/srep28255.

Turner, A. J., C. Frankenberg, P. O. Wennberg, and D. J. Jacob. 2017. Ambiguity in the causes for decadal trends in atmospheric methane and hydroxyl. Proc. Natl. Acad. Sci. USA 114:5367-5372.

Turner, A. J., D. J. Jacob, J. Benmergui, S. C. Wofsy, J. D. Maasakkers, A. Butz, O. Hasekamp, and S. C. Biraud. 2016. A large increase in U.S. methane emissions over the past decade inferred from satellite data and surface observations. Geophys. Res. Lett. 43:2218-2224. https://doi.org/10.1002/2016GL067987.

Tyrrell, H. F., and J. T. Reid. 1965. Prediction of the energy value of cow's milk. J. Dairy Sci. 48:1215-1223. 
Tyrrell, H. F., P. J. Reynolds, and P. W. Moe. 1979. Effect of diet on partial efficiency of acetate use for body tissue synthesis by mature cattle. J. Anim. Sci. 48:598-606.

US EPA (Environmental Protection Agency). 2017. Inventory of U.S. greenhouse gas emissions and sinks: 1990-2015. US EPA, Washington, DC.

van Gastelen, S., M. H. P. W. Visker, J. E. Edwards, E. C. AntunesFernandes, K. A. Hettinga, S. J. J. Alferink, W. H. Hendriks, H. Bovenhuis, H. Smidt, and J. Dijkstra. 2017. Linseed oil and DGAT1 K232A polymorphism: Effects on methane emission, energy and nitrogen metabolism, lactation performance, ruminal fermentation, and rumen microbial composition of Holstein-Friesian cows. J. Dairy Sci. 100:8939-8957.

Velazco, J. I., D. Mayer, S. Zimmerman, and R. Hegarty. 2016. Use of short-term breath measures to estimate daily methane production by cattle. Animal 10:25-33.

Wang, D. T., D. S. Gruen, B. S. Lollar, K.-U. Hinrichs, L. C. Stewart, J. F. Holden, A. N. Hristov, J. W. Pohlman, P. L. Morrill, M. Könneke, K. B. Delwiche, E. P. Reeves, C. N. Sutcliffe, D. J. Ritter, J. S. Seewald, J. C. McIntosh, H. F. Hemond, M. D. Kudo, D. Cardace, T. M. Hoehler, and S. Ono. 2015. Unique nonequilibrium clumped isotope signals in microbial methane. Science 348:428-431. https://doi.org/10.1126/science.aaa4326.

Wecht, K. J., D. J. Jacob, C. Frankenberg, Z. Jiang, and D. R. Blake. 2014. Mapping of North American methane emissions with high spatial resolution by inversion of SCIAMACHY satellite data. J. Geophys. Res. Atmos. 119:7741-7756.

Wolf, J., G. R. Asrar, and T. O. West. 2017. Revised methane emissions factors and spatially distributed annual carbon fluxes for global livestock. Carbon Balance Manag. 12:16. https://doi.org/10 $.1186 / \mathrm{s} 13021-017-0084-y$.

Wu, L., P. W. G. G. Koerkamp, and N. Ogink. 2018. Uncertainty assessment of the breath methane concentration method to determine methane production of dairy cows. J. Dairy Sci. 101:15541564. https://doi.org/10.3168/jds.2017-12710.

Zeitz. J. O., C. R. Soliva, and M. Kreuzer. 2012. Swiss diet types for cattle: how accurately are they reflected by the Intergovernmental Panel on Climate Change default values? J. Integr. Environ. Sci. 9(Supp. 1):199-216.

Zimmerman, P. R. 1993. System for Measuring Metabolic Gas Emissions from Animals. University Corp for Atmospheric Research (UCAR), assignee. Pat. No. 5,265,618.

Zimmerman, P. R., and R. S. Zimmerman. 2012. Method and system for monitoring and reducing ruminant methane production. United States Pat. No. US20090288606 A1. P. R. Zimmerman, assignee.

Zom, R. L. G., G. André, and A. M. van Vuuren. 2012. Development of a model for the prediction of feed intake by dairy cows: 1 . Prediction of feed intake. Livest. Sci. 143:43-57. 